\title{
Discovery of a Dimeric Zinc Complex and Five Cyclopentenone Derivatives from the Sponge-Associated Fungus Aspergillus ochraceopetaliformis
}

Cui Guo, ${ }^{\dagger}, \#$ Pei Wang, ${ }^{\dagger}$ Xiaoyan Pang,${ }^{\dagger}$ Xiuping Lin,${ }^{\dagger,}$ Shengrong Liao,${ }^{\dagger, \S}$ Bin Yang,,${ }^{\dagger, \S}$ Xuefeng Zhou, ${ }^{\dagger, \S}$ Junfeng Wang, ${ }^{*}, \dagger, \S$ and Yonghong Liu ${ }^{*}, \dagger,, \#$

${ }^{\dagger}$ CAS Key Laboratory of Tropical Marine Bio-resources and Ecology/Guangdong Key Laboratory of Marine Materia Medica/RNAM Center for Marine Microbiology/Innovation Academy of South China Sea Ecology and Environmental Engineering, South China Sea Institute of Oceanology, Chinese Academy of Sciences, Guangzhou 510301, China

Institute of Tropical Bioscience and Biotechnology, Chinese Academy of Tropical Agricultural Sciences, Haikou 571101, China

${ }^{\S}$ Southern Marine Science and Engineering Guangdong Laboratory (Guangzhou), Guangzhou 511458, China

\#University of Chinese Academy of Sciences, Beijing 100049, China

Corresponding Author

*E-mail: wangjunfeng@sscsio.ac.cn; yonghongliu@scsio.ac.cn 


\section{Contents of Supporting Information}

The strain's (Aspergillus ochraceopetaliformis SCSIO 41018) ITS sequence of the rDNA.

Table S1. ${ }^{1} \mathrm{H}$ and ${ }^{13} \mathrm{C}$ NMR data for compound 1 in DMSO- $d_{6}(700,175 \mathrm{MHz})$.

Table S2. Cytotoxic activities of compound $\mathbf{1}\left(\mathrm{IC}_{50}, \mu \mathrm{M}\right)$

Figure S1.The scanning electron microscopic image of Aspergillus ochraceopetaliformis SCSIO 41018........S6

Figure S2.The X-ray photoelectron spectroscopy of dizinchydroxyneoaspergillin (1) .......................................S7

Figure S3. The ${ }^{1} \mathrm{H}$ NMR spectrum of dizinchydroxyneoaspergillin (1) in DMSO- $d_{6}(500 \mathrm{MHz})$........................S7

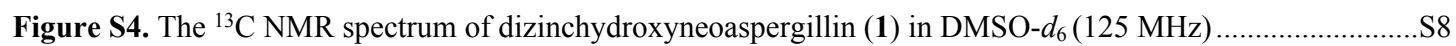

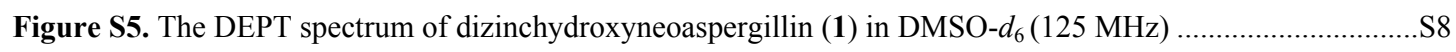

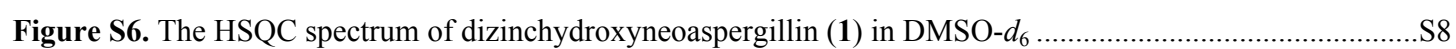

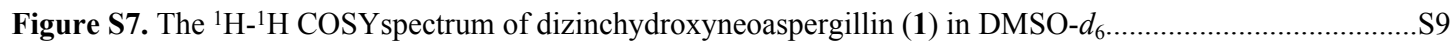

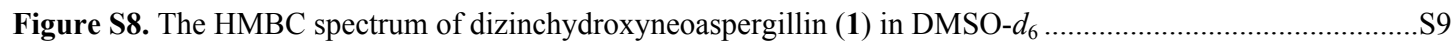

Figure S9. The HRESIMS spectrum of dizinchydroxyneoaspergillin (1) .......................................................S10

Figure S10. The UV spectrum of dizinchydroxyneoaspergillin (1) ...............................................................

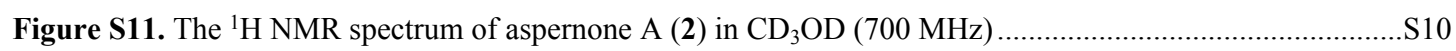

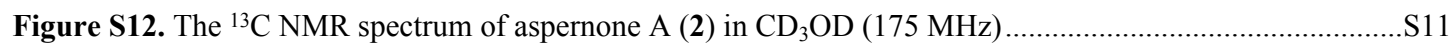

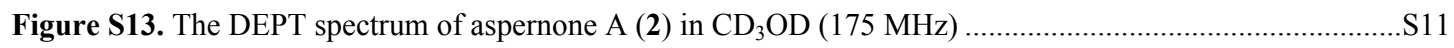

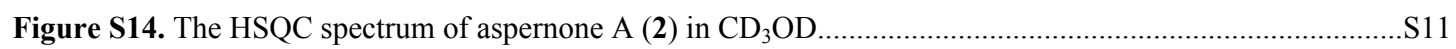

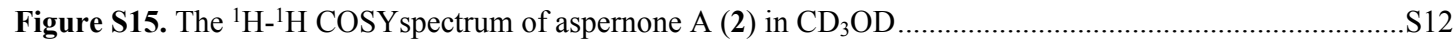

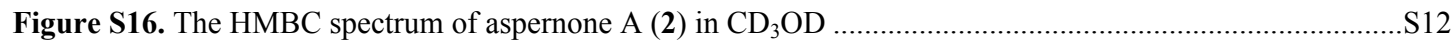

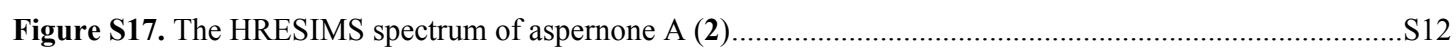

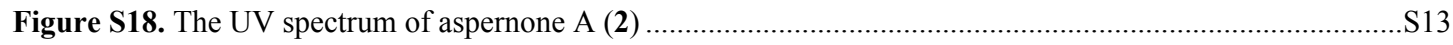

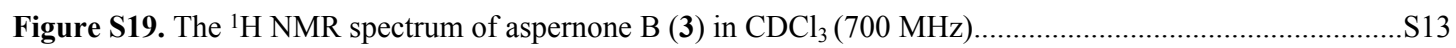

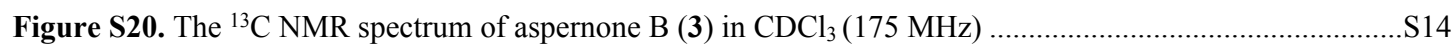

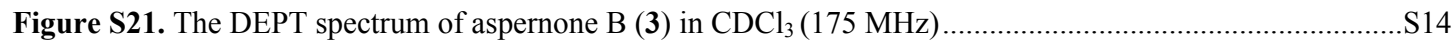

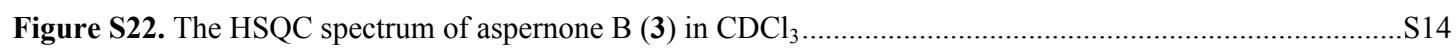

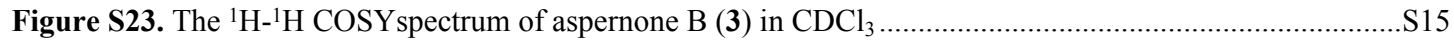

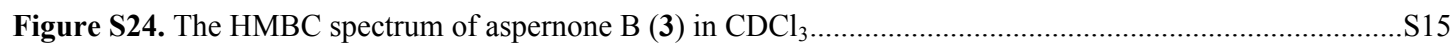

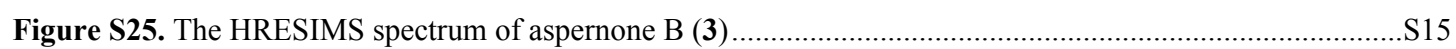

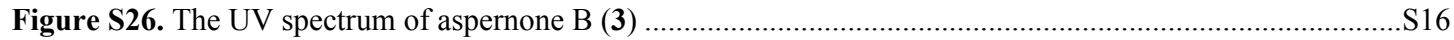

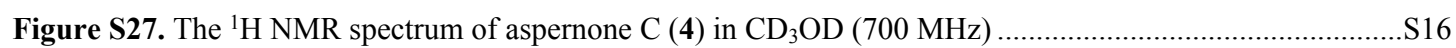

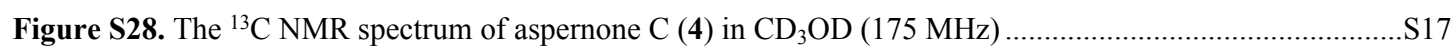

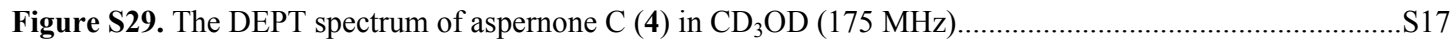

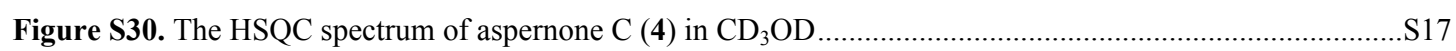

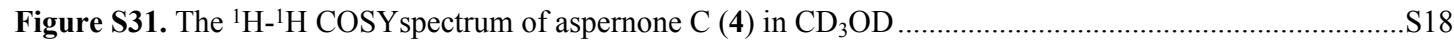

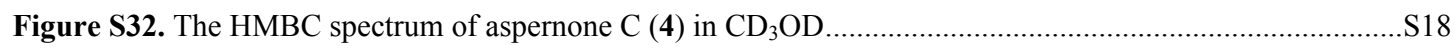

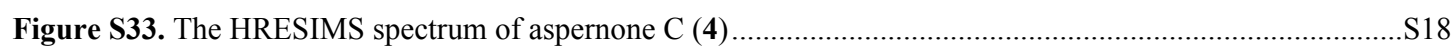

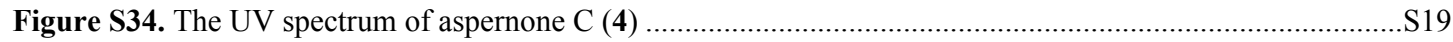

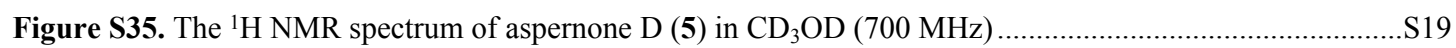

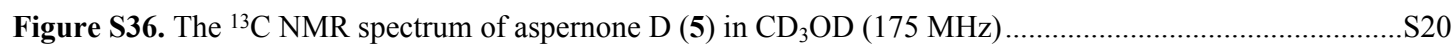

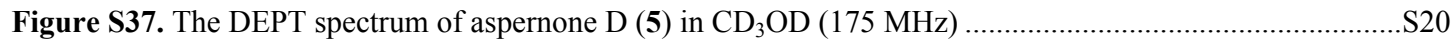

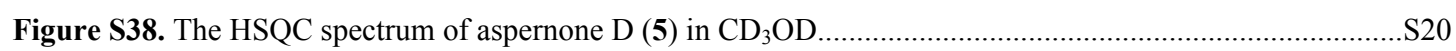

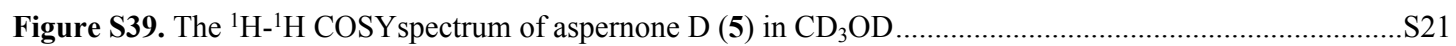

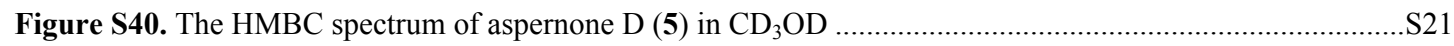


Figure S41. The NOESY spectrum of aspernone D (5) in $\mathrm{CD}_{3} \mathrm{OD}$

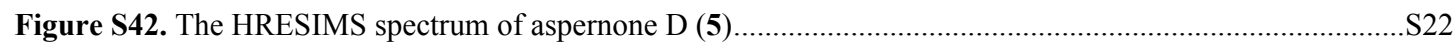

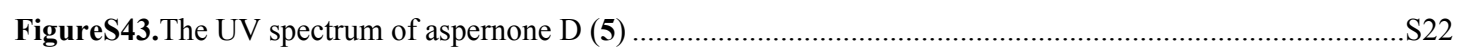

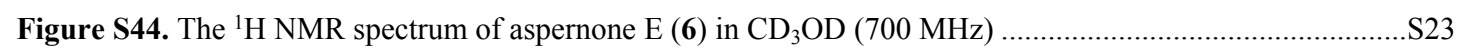

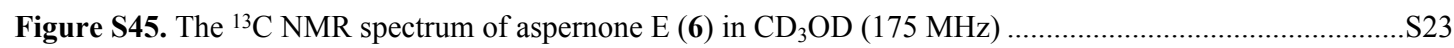

Figure S46. The DEPT spectrum of aspernone $\mathrm{E}(\mathbf{6})$ in $\mathrm{CD}_{3} \mathrm{OD}(175 \mathrm{MHz})$......................................................S23

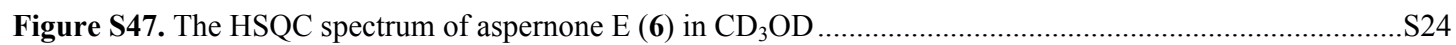

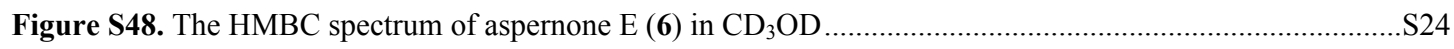

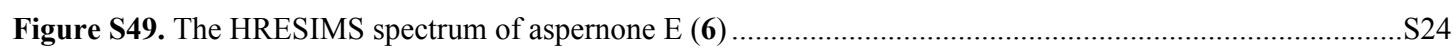

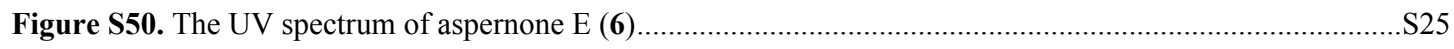


The strain's (Aspergillus ochraceopetaliformis SCSIO 41018) ITS sequence of the rDNA.

CCTGCGGAAGGATCATTACTGAGTGAGGGTTCCTTCGGGGCCCAACCTCCCACCCTTG TATACTGTACCAAGTTGCTTCGGCGGGCCCGCCGTTCGCGCGGCCGCCGGGGGGGAA CCCCTCCCCCCGGGCGAGCGCCCGCCGGAGACCCCAACGTGAACACTGTCTGAAGTT TTGTCGTCTGAGTTCGATTGTATCGCAATCAGTTAAAACTTTCAACAATGGATCTCTT GGTTCCGGCATCGATGAAGAACGCAGCGAAATGCGATAATTAATGTGAATTGCAGAA TTCAGTGAATCATCGAGTCTTTGAACGCACATTGCACCCCCTGGTATTCCGGGGGGTA TGCCTGTCCGAGCGTCATTGCTGCCCTCAAGCCCGGCTTGTGTGTTGGGTCCTCGTCC CCCCCGGGGGACGGGCCCGAAAGGCAGCGGCGGCACCGCGTCCGGTCCTCGAGCGTA TGGGGCTTTGTCACACCGCTCTCGTAGGCCCGGCCGGCGCTGGCCGACGCTGAAAAG CAACCATTATTTCTCCAGGTTGACCTCGGATCAGGTAGGGATACCCGCTGAACTTAAG CATATCAATA 
Table S1. ${ }^{1} \mathrm{H}$ and ${ }^{13} \mathrm{C}$ NMR data for compound 13 in DMSO- $d_{6}(700,175 \mathrm{MHz})$.

\begin{tabular}{lll} 
& \multicolumn{2}{c}{$\mathbf{1 3}$} \\
\cline { 2 - 3 } no & $\delta_{\mathrm{H}}(\mathrm{J}$ in Hz) & $\delta_{\mathrm{C}}$ \\
2 & & 154.2 \\
3 & & 155.3 \\
4 & & \\
5 & $7.26, \mathrm{~s}$ & 119.9 \\
6 & & 142.8 \\
$1^{\prime}$ & $4.63, \mathrm{~d}(4.0)$ & 72.1 \\
$2^{\prime}$ & $2.14, \mathrm{~m}$ & 33.3 \\
$3^{\prime}$ & $0.94, \mathrm{~d}(6.8)$ & 19.8 \\
$4^{\prime}$ & $0.79, \mathrm{~d}(6.7)$ & 16.5 \\
$1^{\prime \prime}$ & $2.62, \mathrm{dd}(13.7,7.2)$ & 42.7 \\
$2^{\prime \prime}$ & $2.05, \mathrm{~m}$ & 28.3 \\
$3^{\prime \prime}$ & $0.89, \mathrm{~d}(6.6)$ & 22.9 \\
$4^{\prime \prime}$ & $0.89, \mathrm{~d}(6.6)$ & 22.8
\end{tabular}

Table S2. Cytotoxic activities of compound $\mathbf{1}\left(\mathrm{IC}_{50}, \mu \mathrm{M}\right)$.

\begin{tabular}{lccccc} 
Compounds & \multicolumn{5}{c}{$\mathrm{IC}_{50}, \mu \mathrm{M}$} \\
\cline { 2 - 6 } & $\mathrm{K} 562$ & BEL-7402 & SGC-7901 & A549 & Hela \\
$\mathbf{1}$ & $12.88 \pm 0.14$ & $15.83 \pm 0.23$ & $15.08 \pm 0.62$ & $>30$ & $>30$ \\
Paclitaxel & $1.01 \pm 0.13$ & $0.76 \pm 0.04$ & $1.44 \pm 0.48$ & $3.81 \pm 0.26$ & $1.02 \pm 0.09$
\end{tabular}




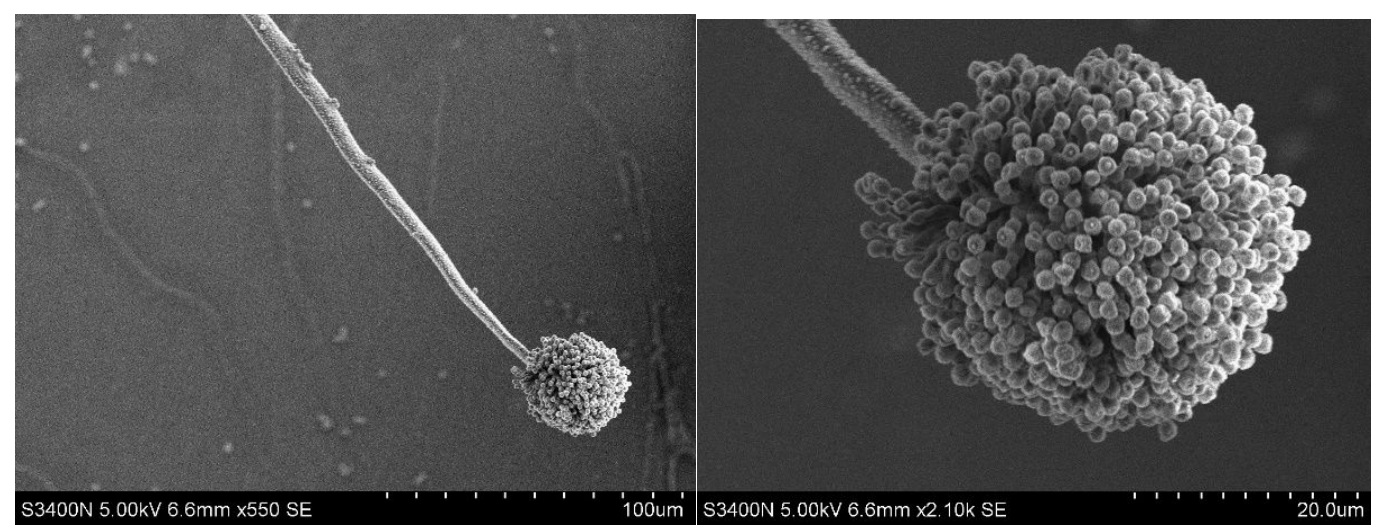

Figure S2.The scanning electron microscopic image of Aspergillus ochraceopetaliformis SCSIO 41018

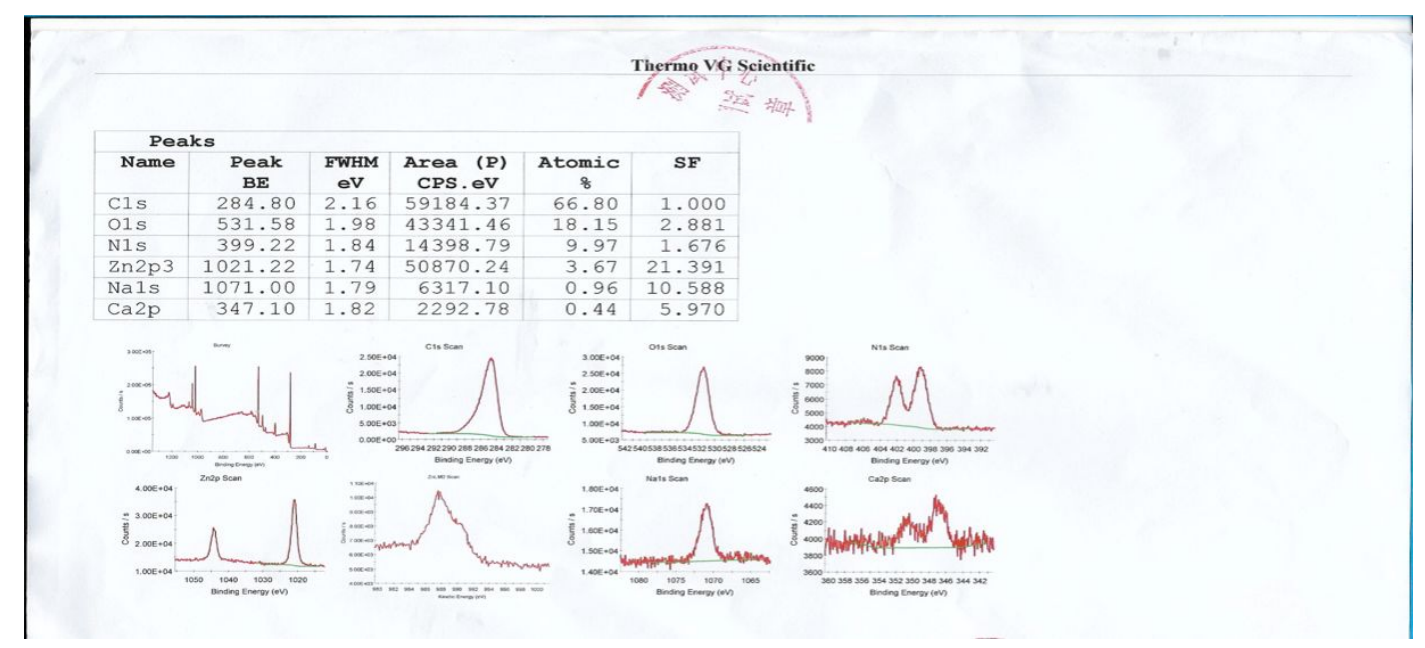

Figure S2.The X-ray photoelectron spectroscopy of dizinchydroxyneoaspergillin (1) (Legent: instrument: photoelectron spectrometer Thermo ESCALAB 250; vacuum: $1.9 * 10^{-7} \mathrm{~Pa}$; X-ray: Al $\mathrm{K} \alpha$ (1486.6 eV; 155W); Scanning mode: CAE; A1 Thermol Library; scanning range: Li3 U92) 


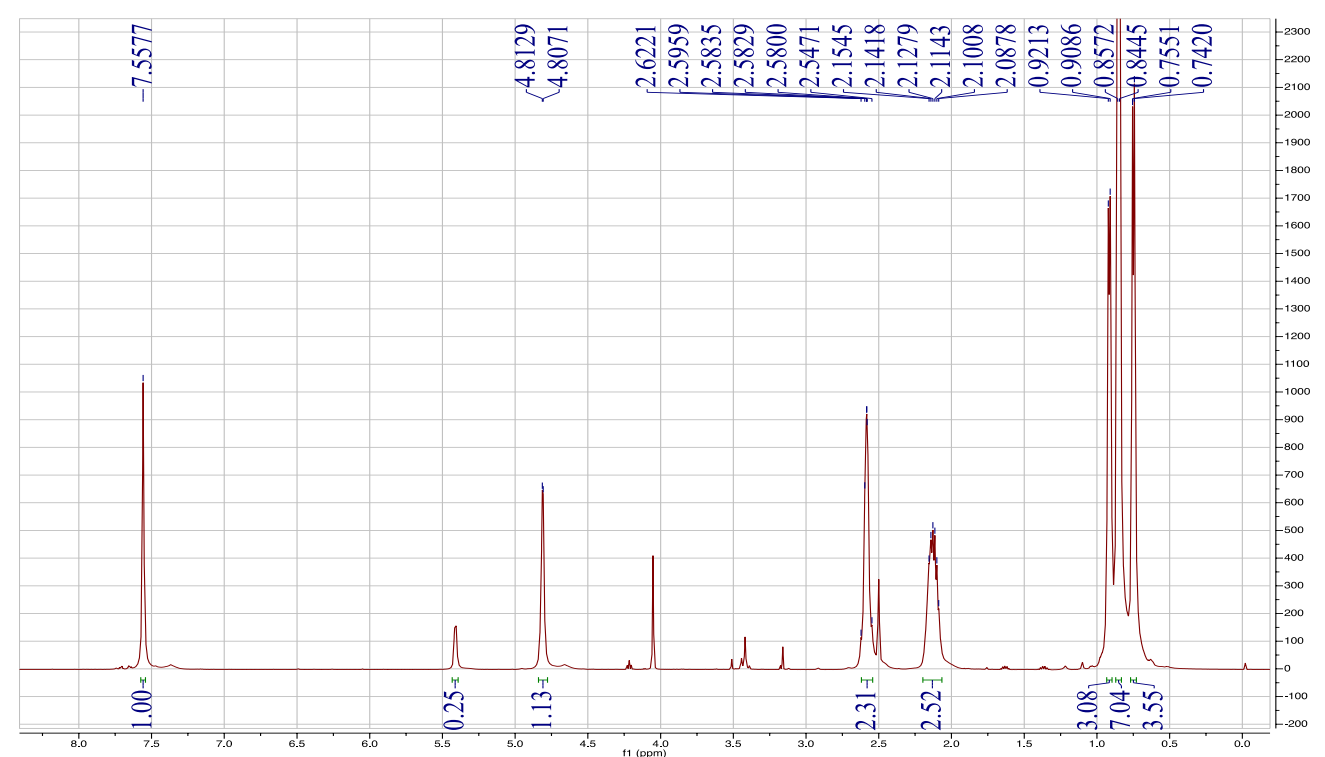

Figure S3. The ${ }^{1} \mathrm{H}$ NMR spectrum of dizinchydroxyneoaspergillin (1) in DMSO- $d_{6}$

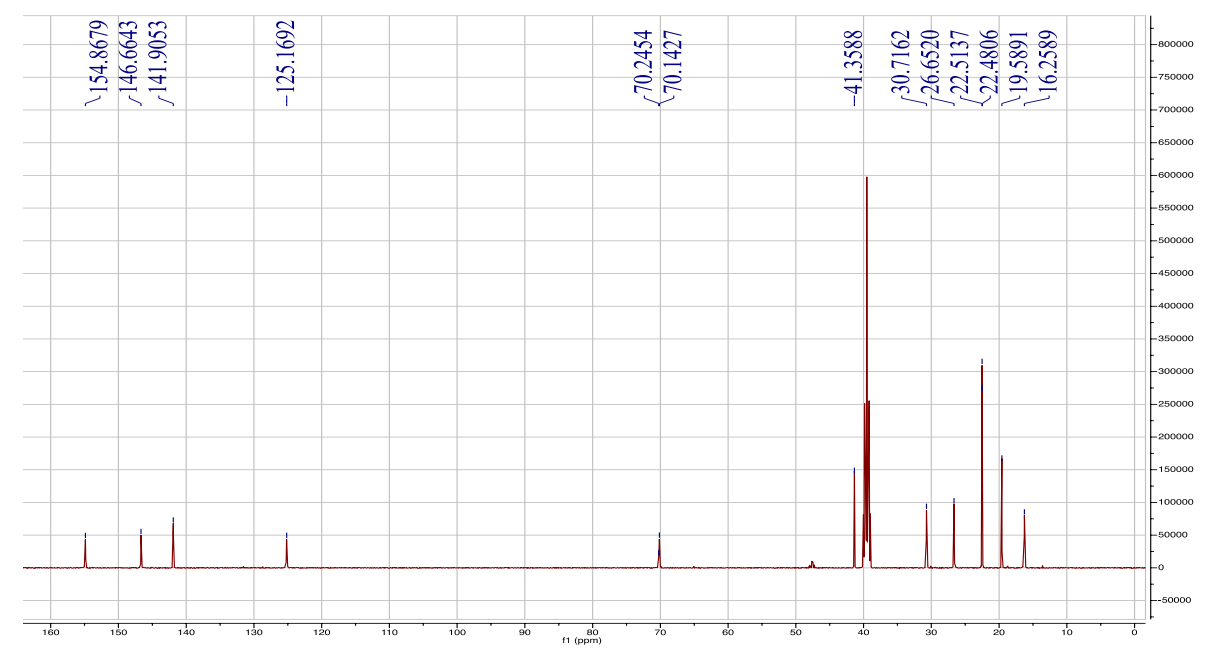

Figure S4. The ${ }^{13} \mathrm{C}$ NMR spectrum of dizinchydroxyneoaspergillin (1) in DMSO- $d_{6}$

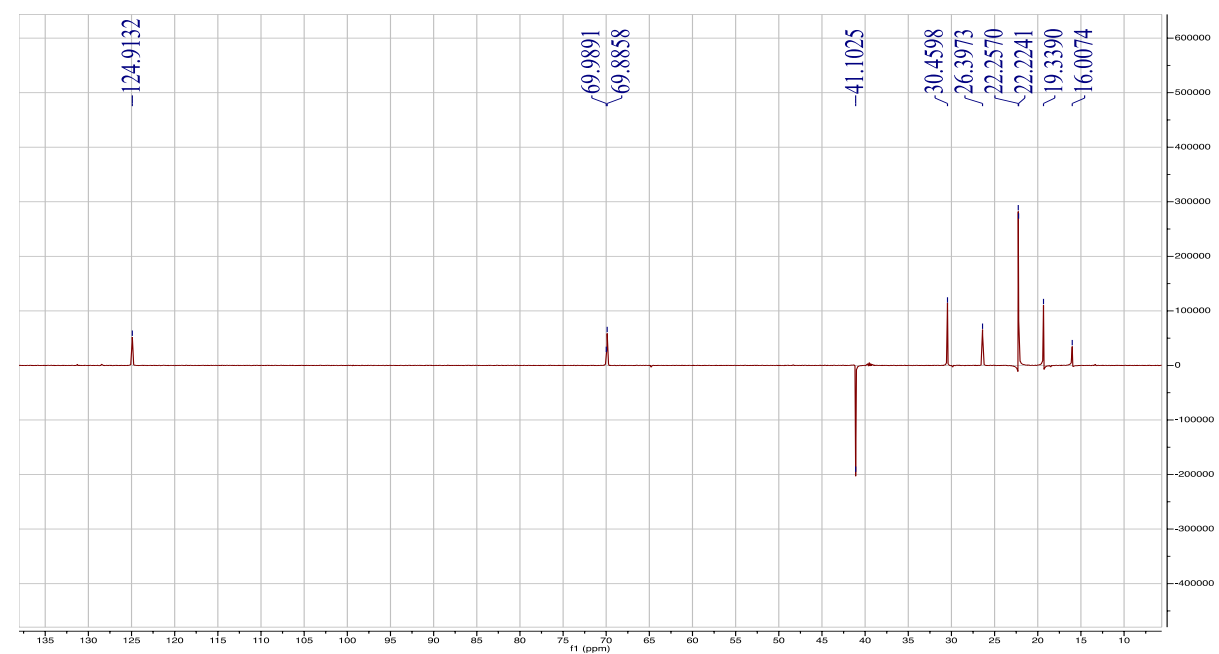

Figure S5. The DEPT spectrum of dizinchydroxyneoaspergillin (1) in DMSO- $d_{6}$ 


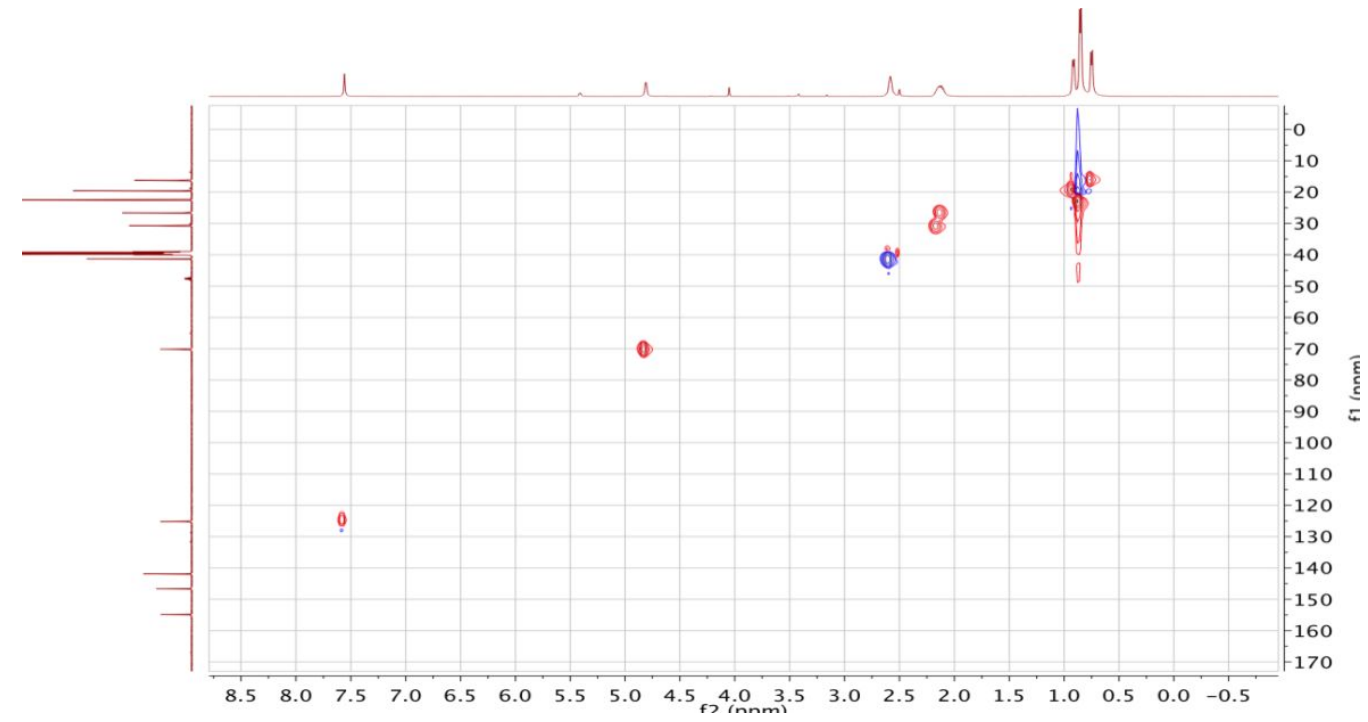

Figure S6. The HSQC spectrum of dizinchydroxyneoaspergillin (1) in DMSO- $d_{6}$

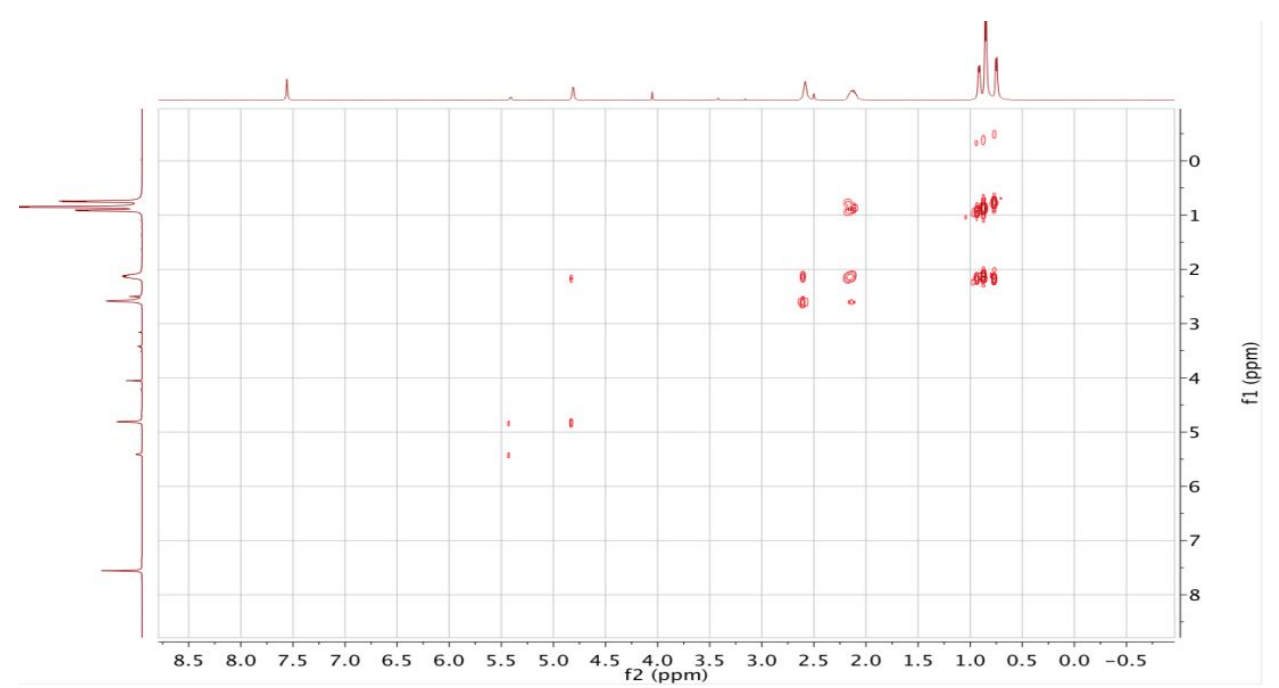

Figure S7. The ${ }^{1} \mathrm{H}-{ }^{1} \mathrm{H}$ COSY spectrum of dizinchydroxyneoaspergillin (1) in DMSO- $d_{6}$

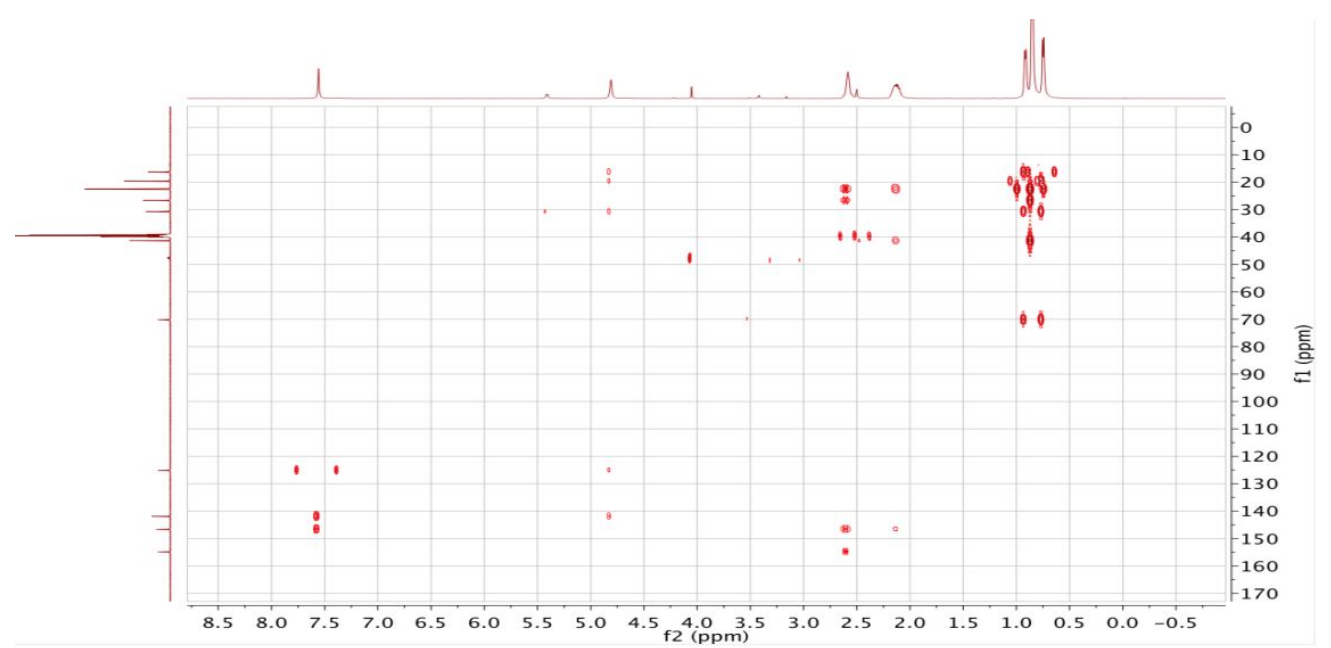

Figure S8. The HMBC spectrum of dizinchydroxyneoaspergillin (1) in DMSO- $d_{6}$ 


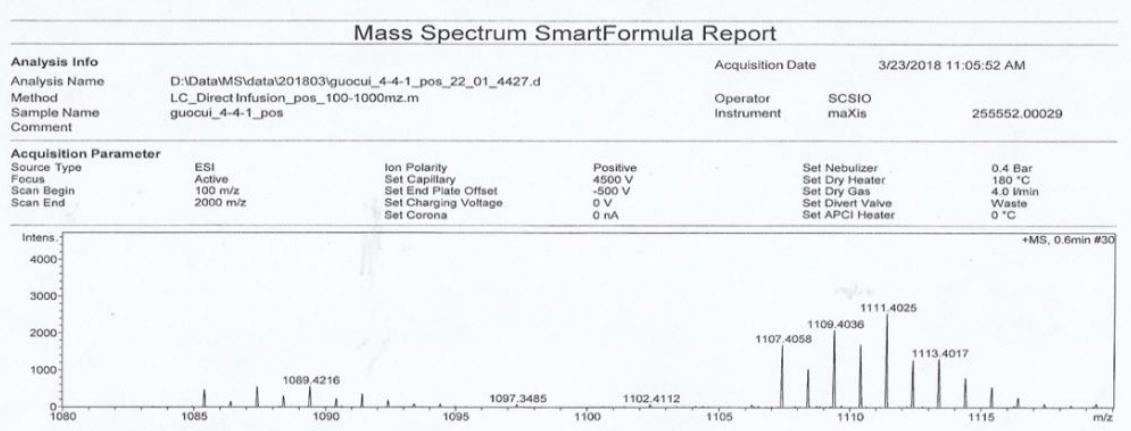

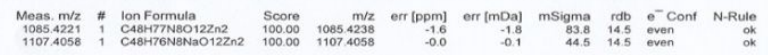

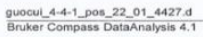

Figure S9. The HRESIMS spectrum of dizinchydroxyneoaspergillin (1)

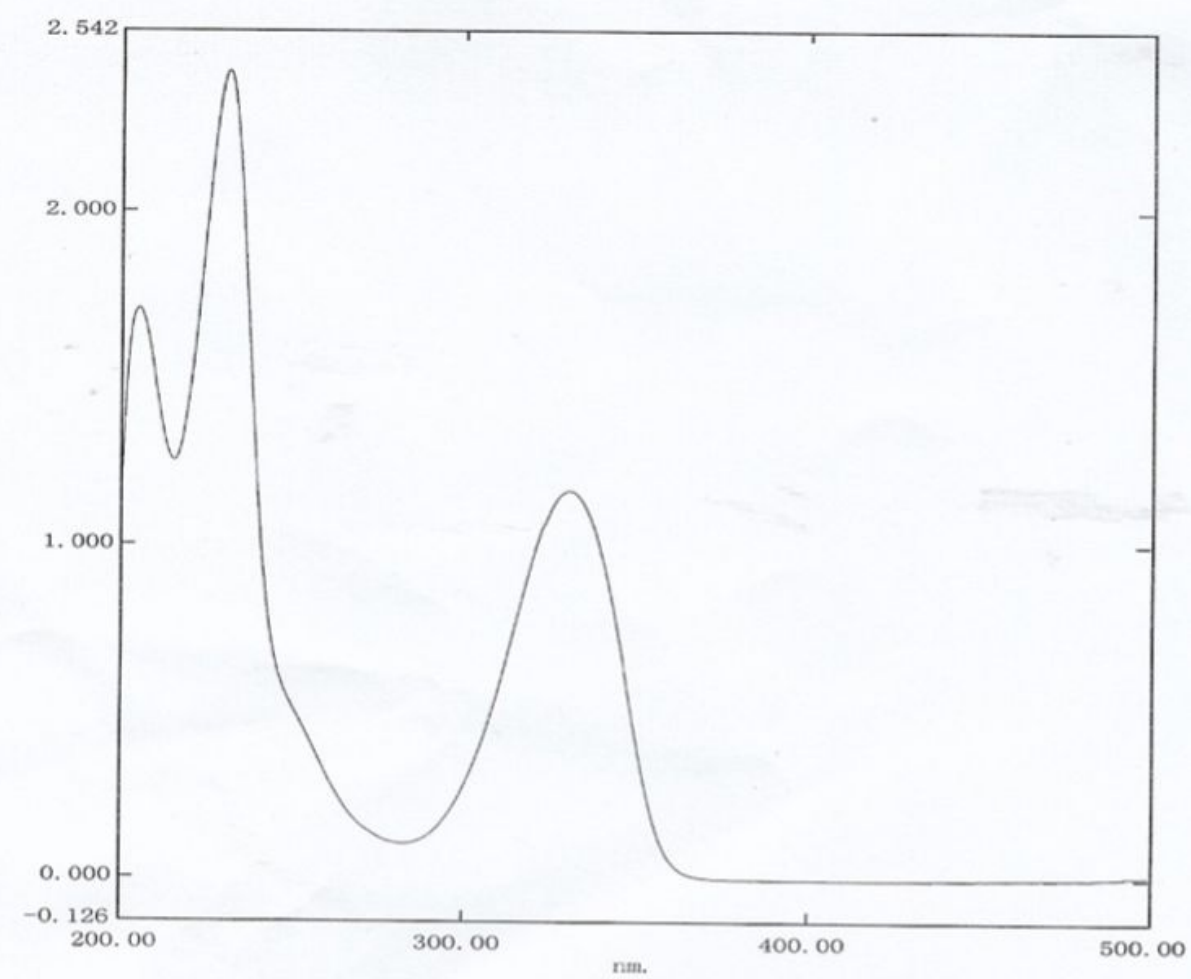

\begin{tabular}{|r|r|r|r|l|}
\hline No. & $\mathrm{P} / \mathrm{V}$ & 波长 $(\mathrm{nm})$ & 㖟收值 & 撗述 \\
\hline 1 & ( & 330.20 & 1.162 & \\
\hline 2 & ( & 231.20 & 2.421 & \\
\hline 3 & ( & 205.20 & 1.711 & \\
\hline
\end{tabular}

Figure S10. The UV spectrum of dizinchydroxyneoaspergillin (1) 


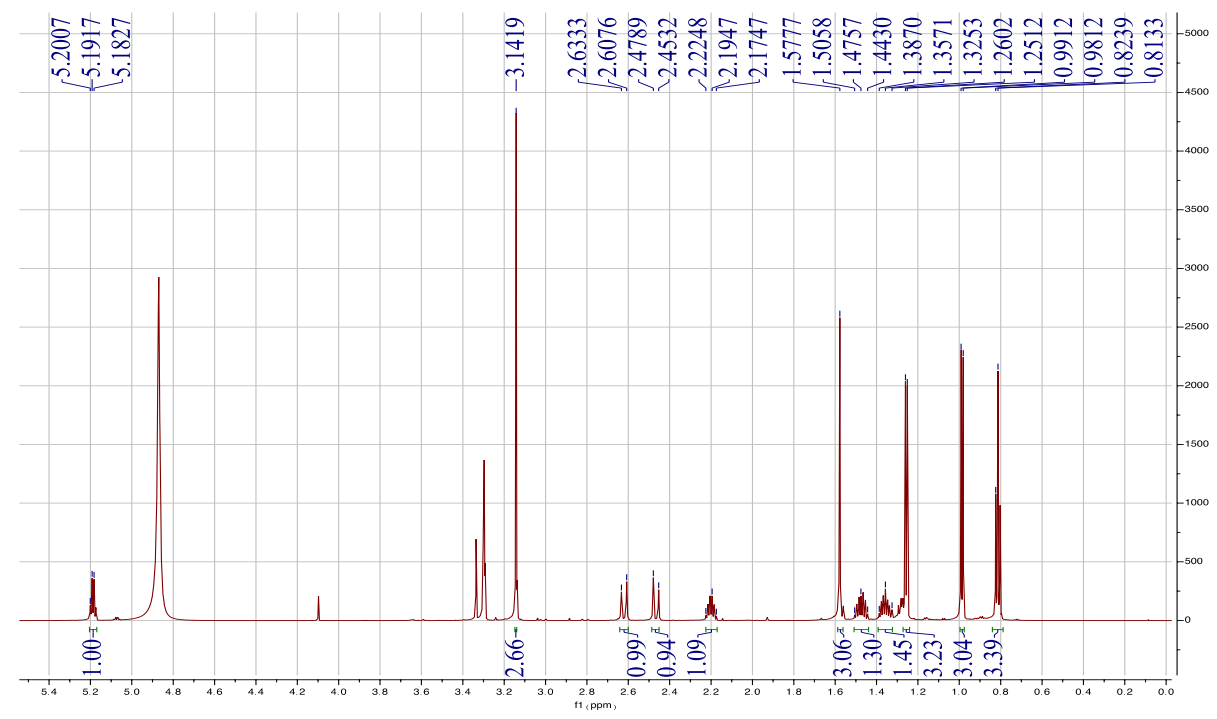

Figure S11. The ${ }^{1} \mathrm{H}$ NMR spectrum of aspernone $\mathrm{A}(2)$ in $\mathrm{CD}_{3} \mathrm{OD}$

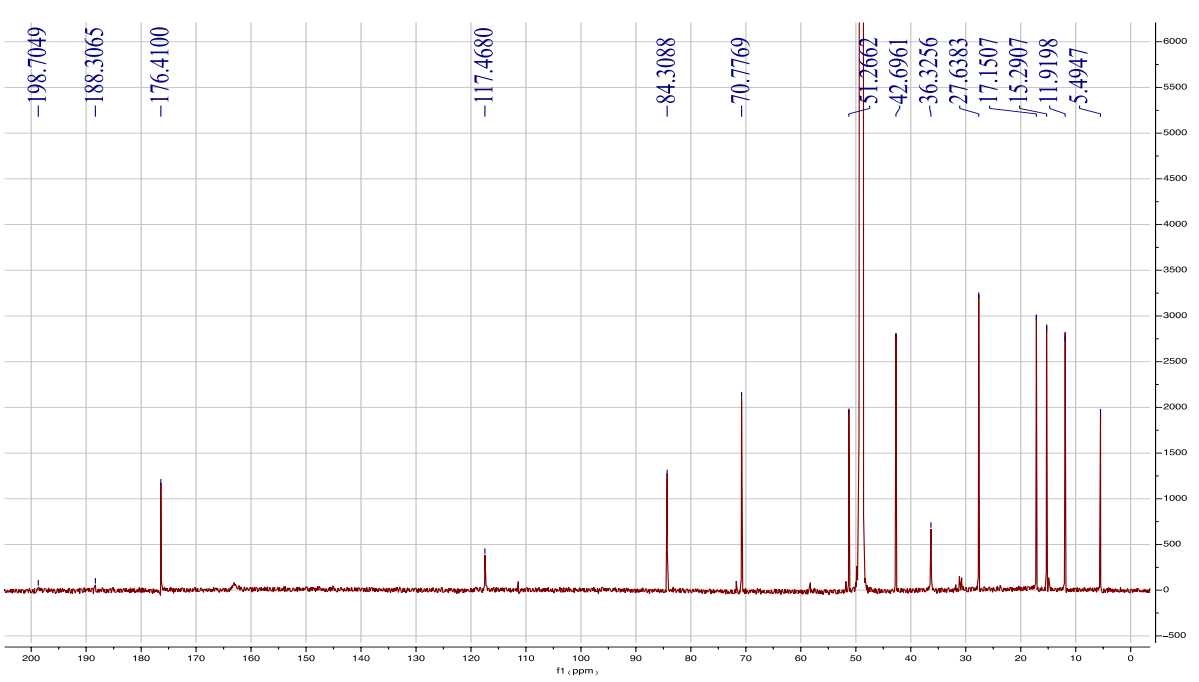

Figure S12. The ${ }^{13} \mathrm{C}$ NMR spectrum of aspernone $\mathrm{A}(2)$ in $\mathrm{CD}_{3} \mathrm{OD}$

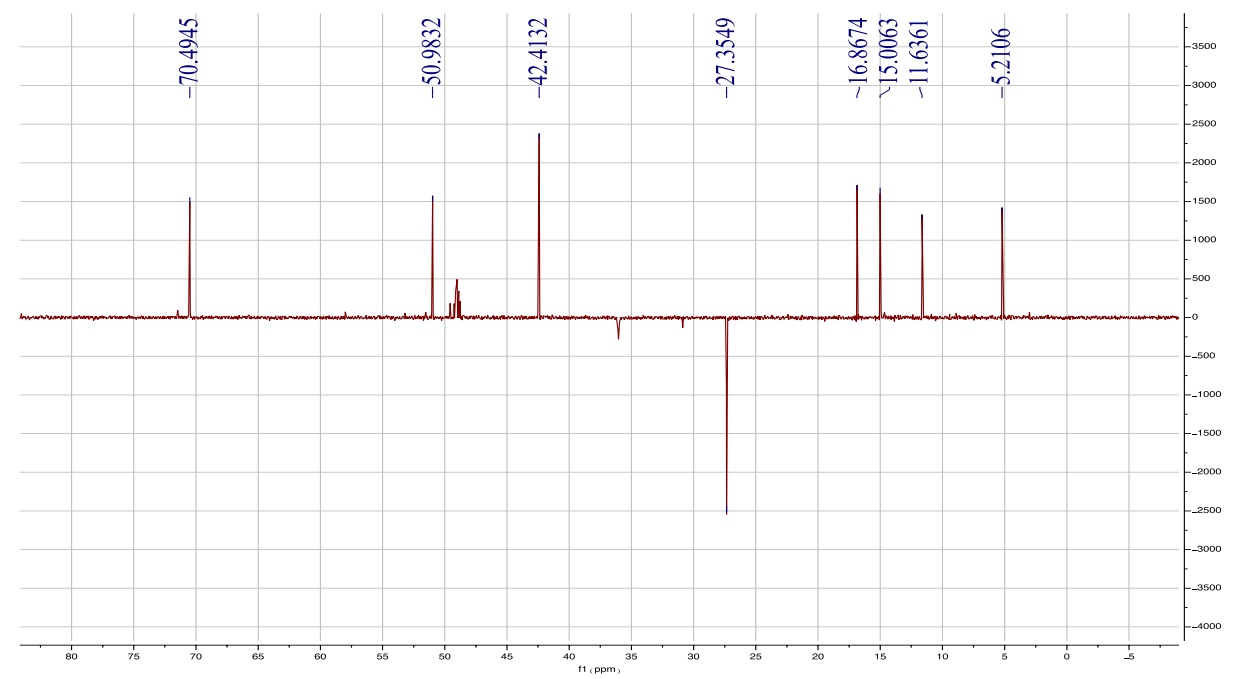

Figure S13. The DEPT spectrum of aspernone $\mathrm{A}(2)$ in $\mathrm{CD}_{3} \mathrm{OD}$ 


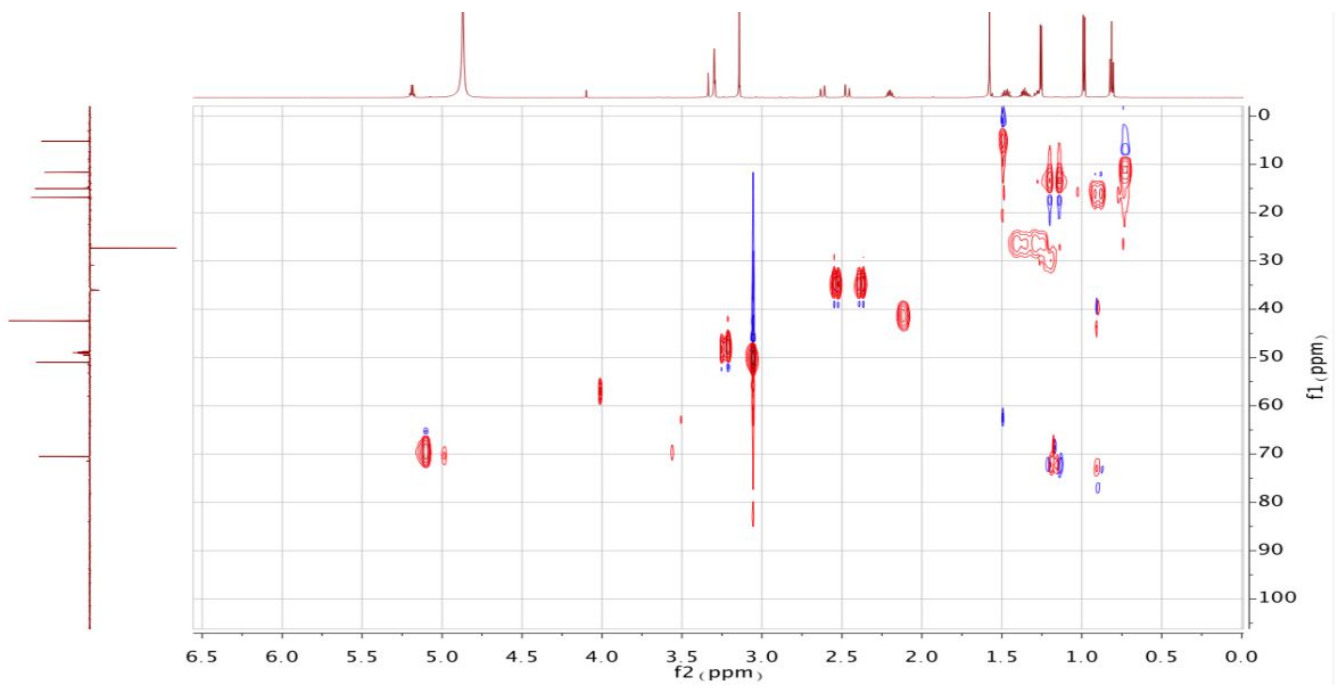

Figure S14. The HSQC spectrum of aspernone A (2) in $\mathrm{CD}_{3} \mathrm{OD}$

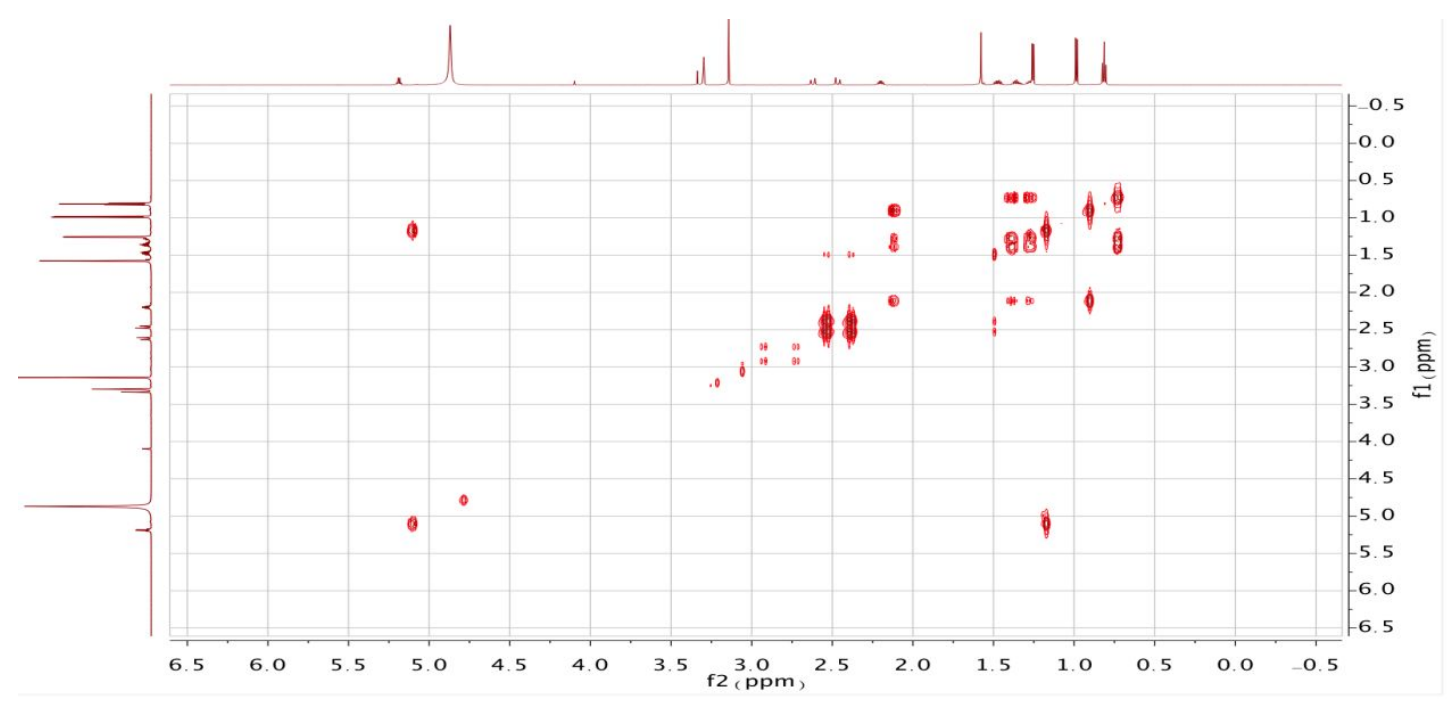

Figure S15. The ${ }^{1} \mathrm{H}-{ }^{1} \mathrm{H}$ COSY spectrum of aspernone $\mathrm{A}(2)$ in $\mathrm{CD}_{3} \mathrm{OD}$

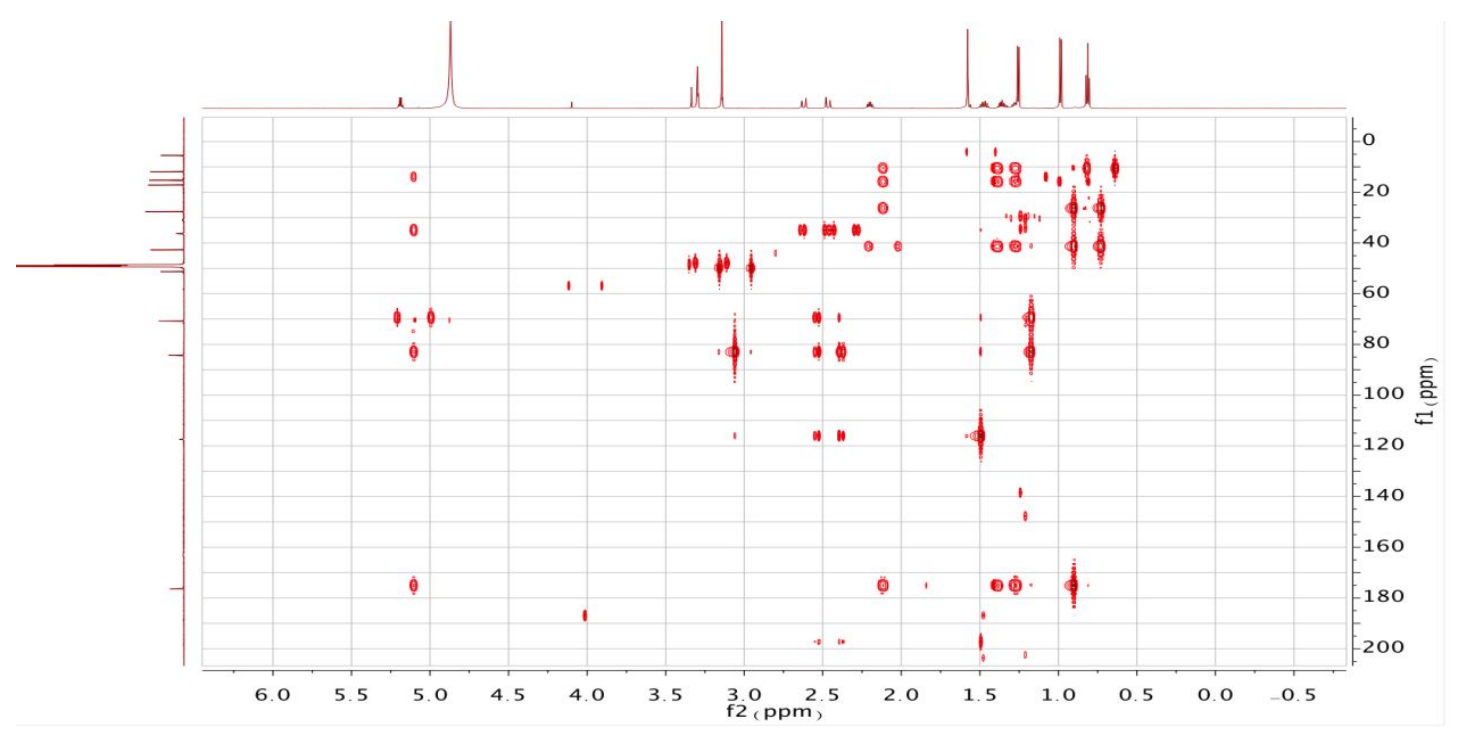

Figure S16. The $\mathrm{HMBC}$ spectrum of aspernone $\mathrm{A}(2)$ in $\mathrm{CD}_{3} \mathrm{OD}$ 


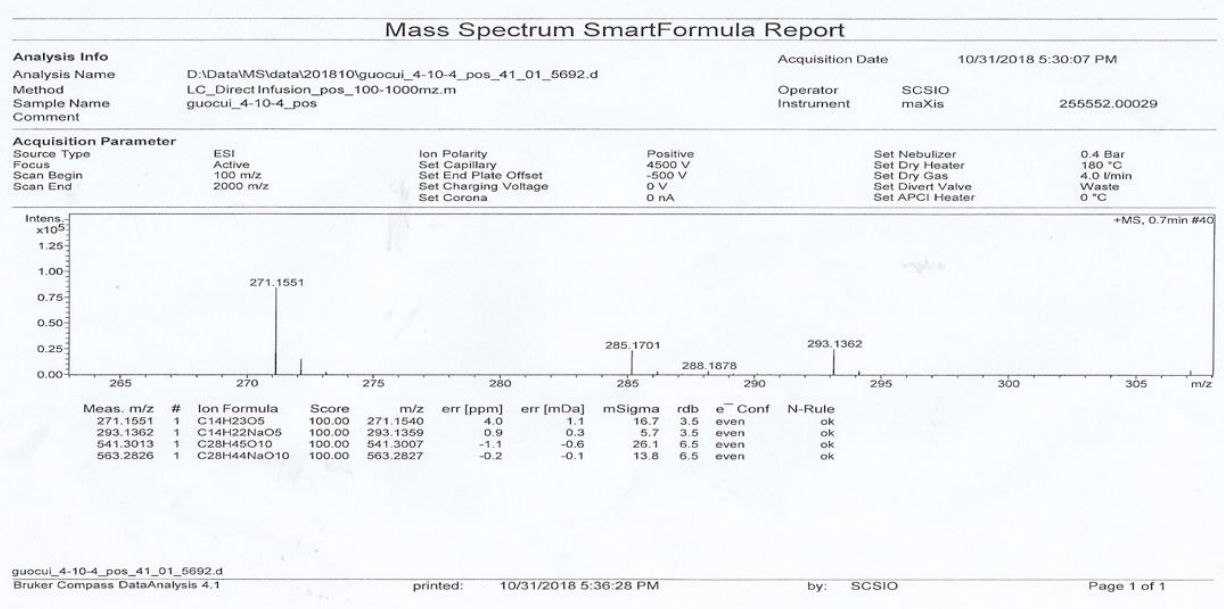

Figure S17. The HRESIMS spectrum of aspernone A (2)

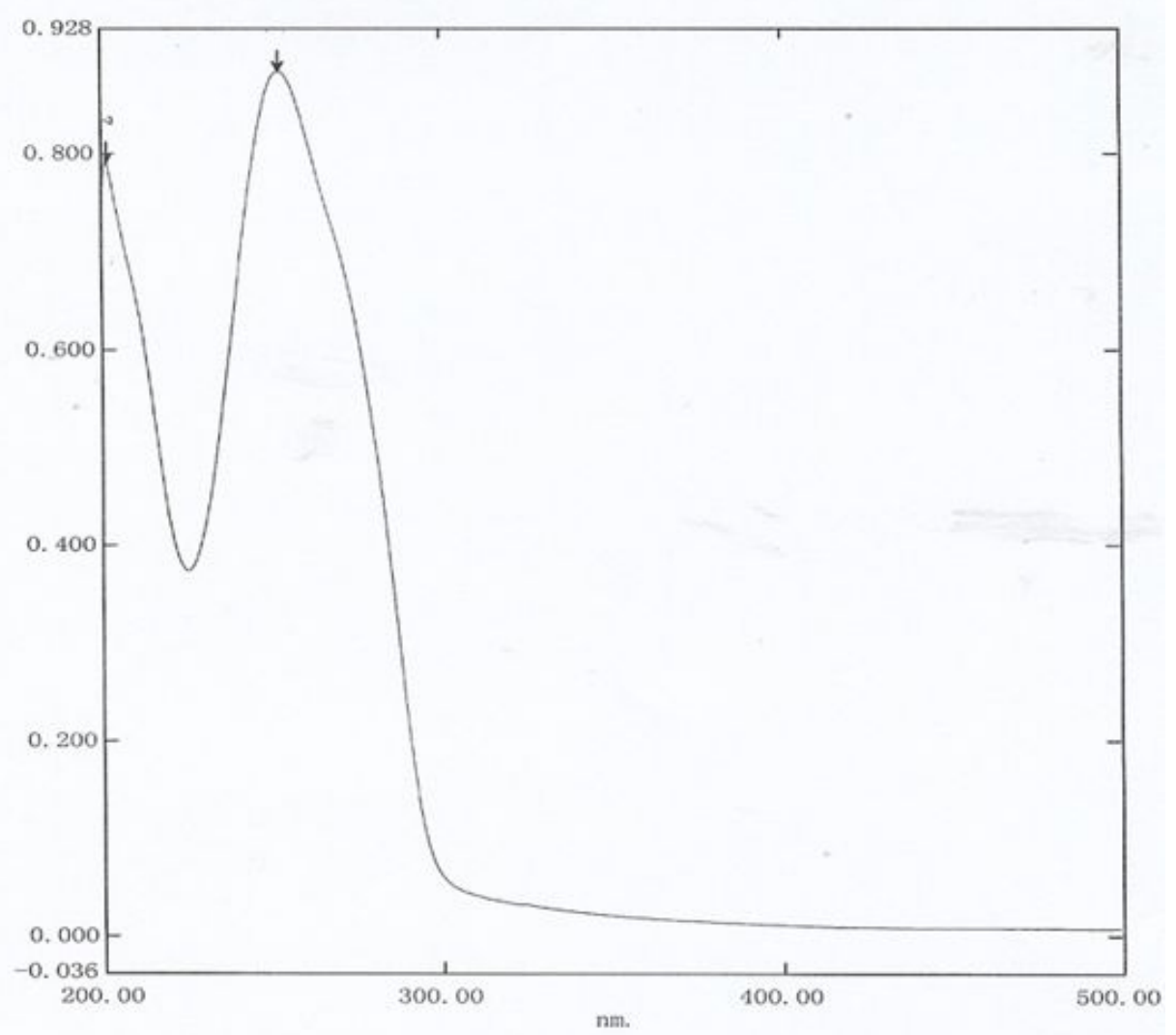

No.

\begin{tabular}{|l|r|r|r|}
\hline P/V & 波长 $(\mathrm{nm})$ & 吸收值 & 描述 \\
\hline (T) & 252.80 & 0.885 & \\
\hline () & 201.40 & 0.792 & \\
\hline
\end{tabular}

Figure S18. The UV spectrum of aspernone A (2) 


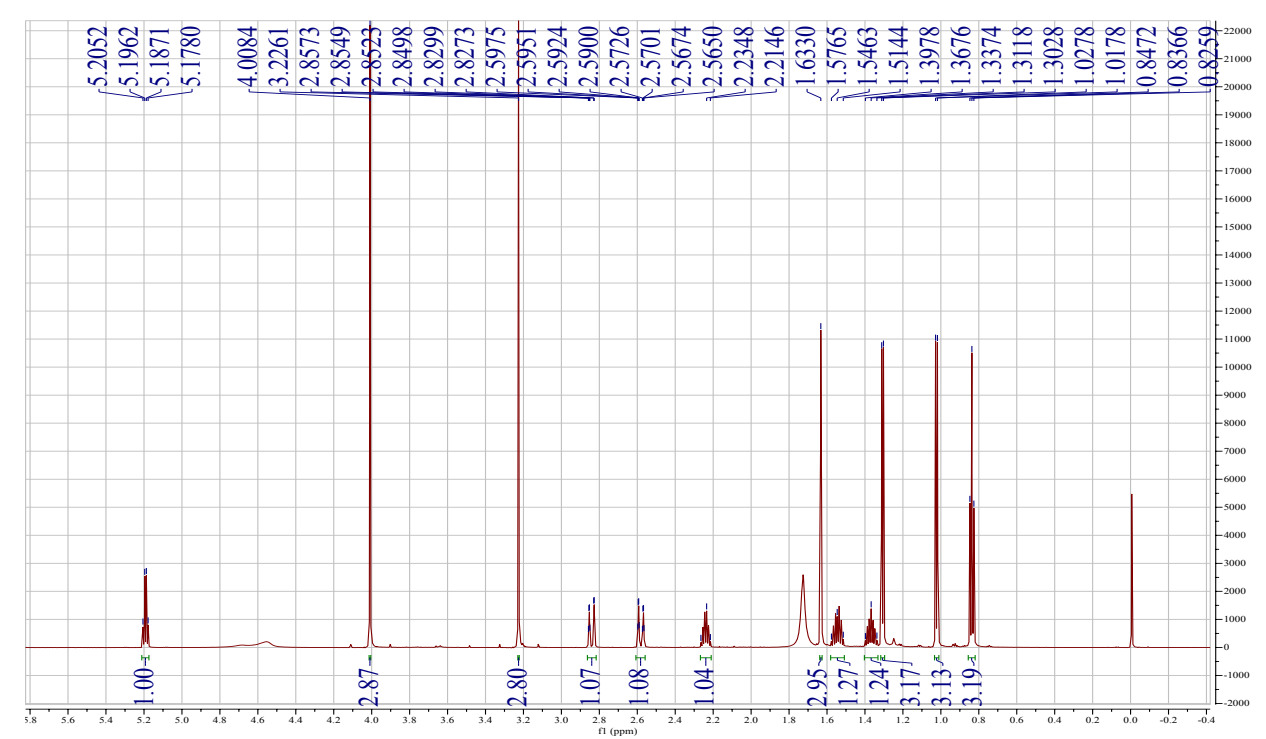

Figure S19. The ${ }^{1} \mathrm{H}$ NMR spectrum of aspernone $\mathrm{B}(3)$ in $\mathrm{CDCl}_{3}$

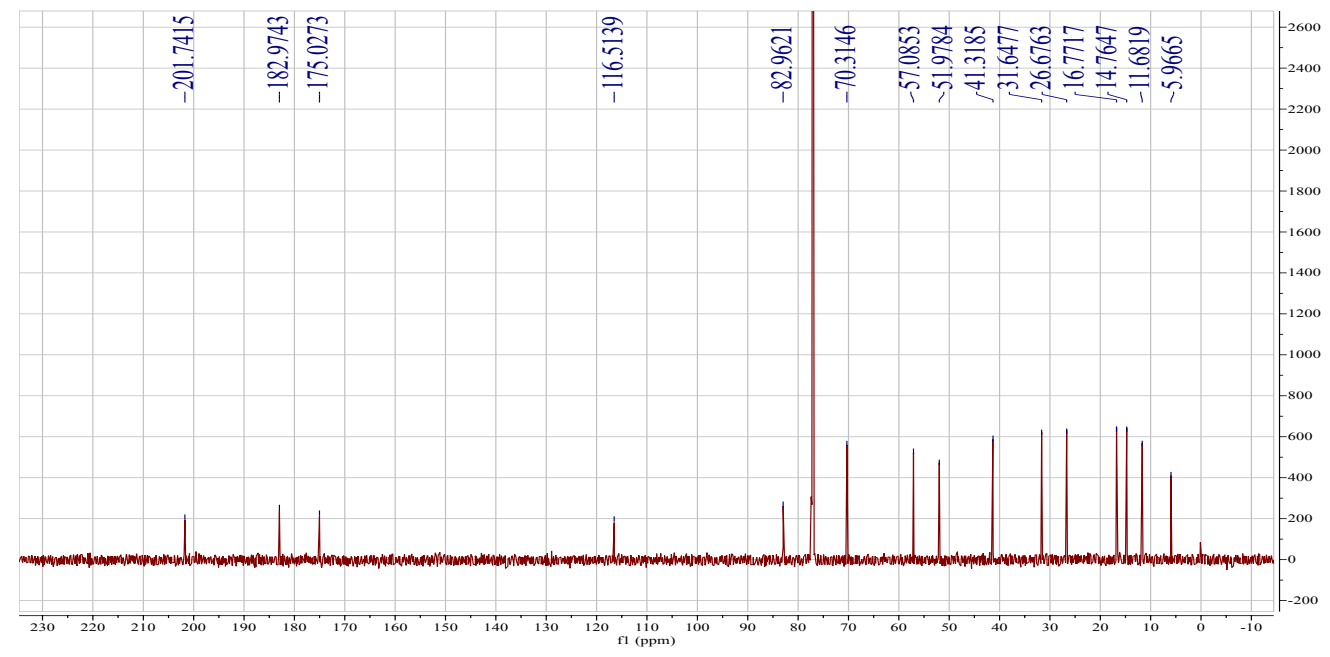

Figure S20. The ${ }^{13} \mathrm{C}$ NMR spectrum of aspernone $\mathrm{B}(3)$ in $\mathrm{CDCl}_{3}$

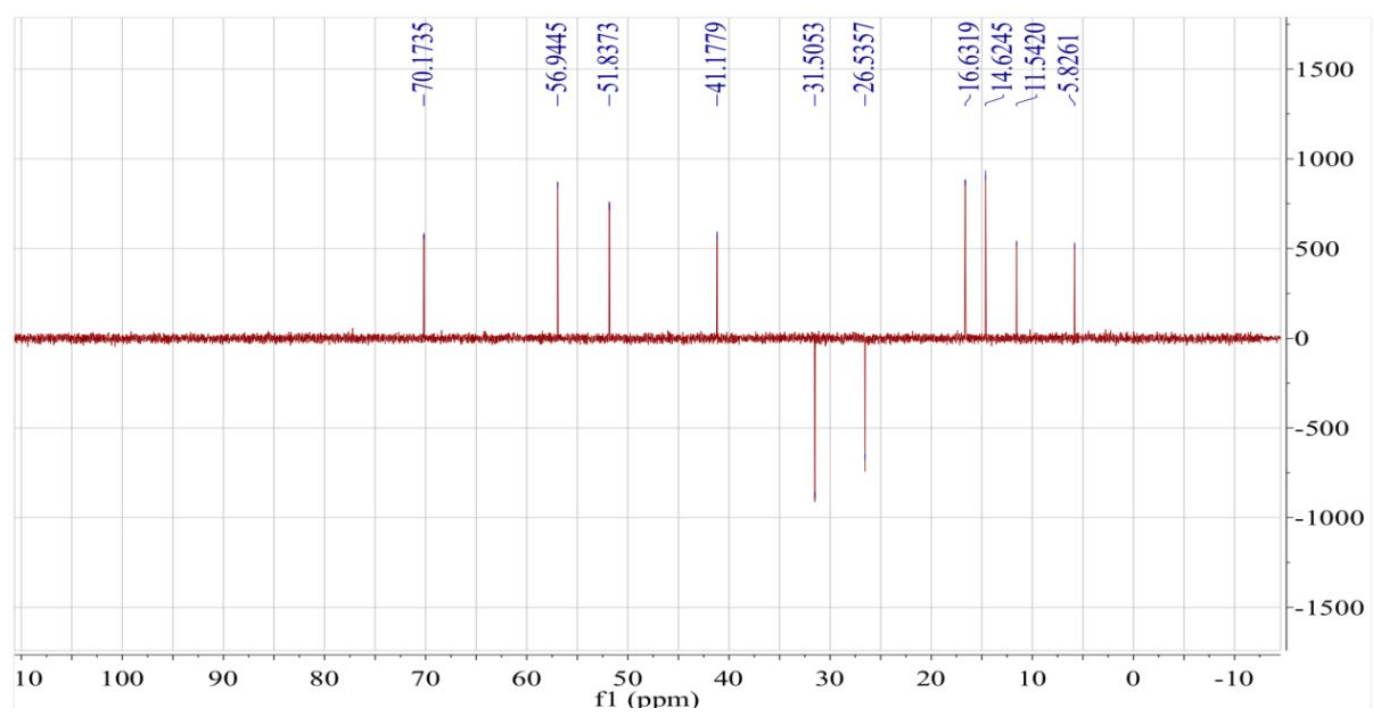

Figure S21. The DEPT spectrum of aspernone $\mathrm{B}(\mathbf{3})$ in $\mathrm{CDCl}_{3}$ 


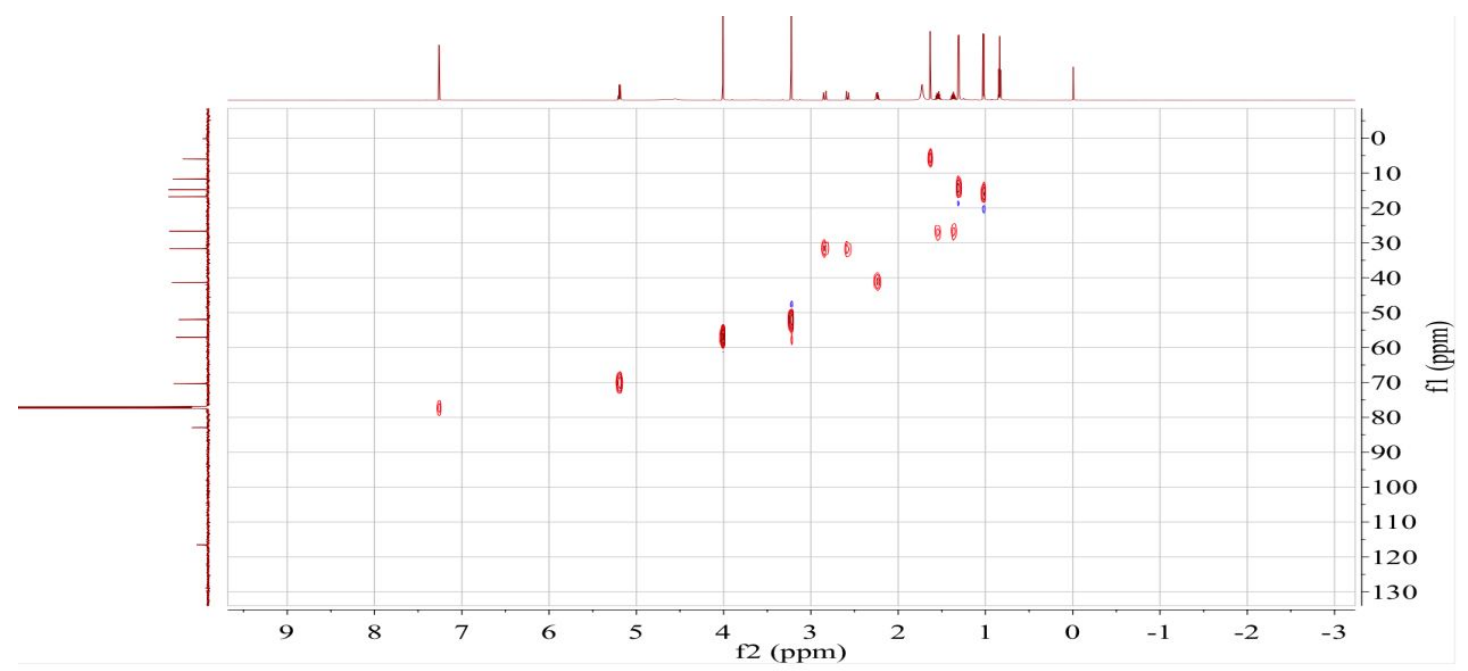

Figure S22. The HSQC spectrum of aspernone B (3) in $\mathrm{CDCl}_{3}$

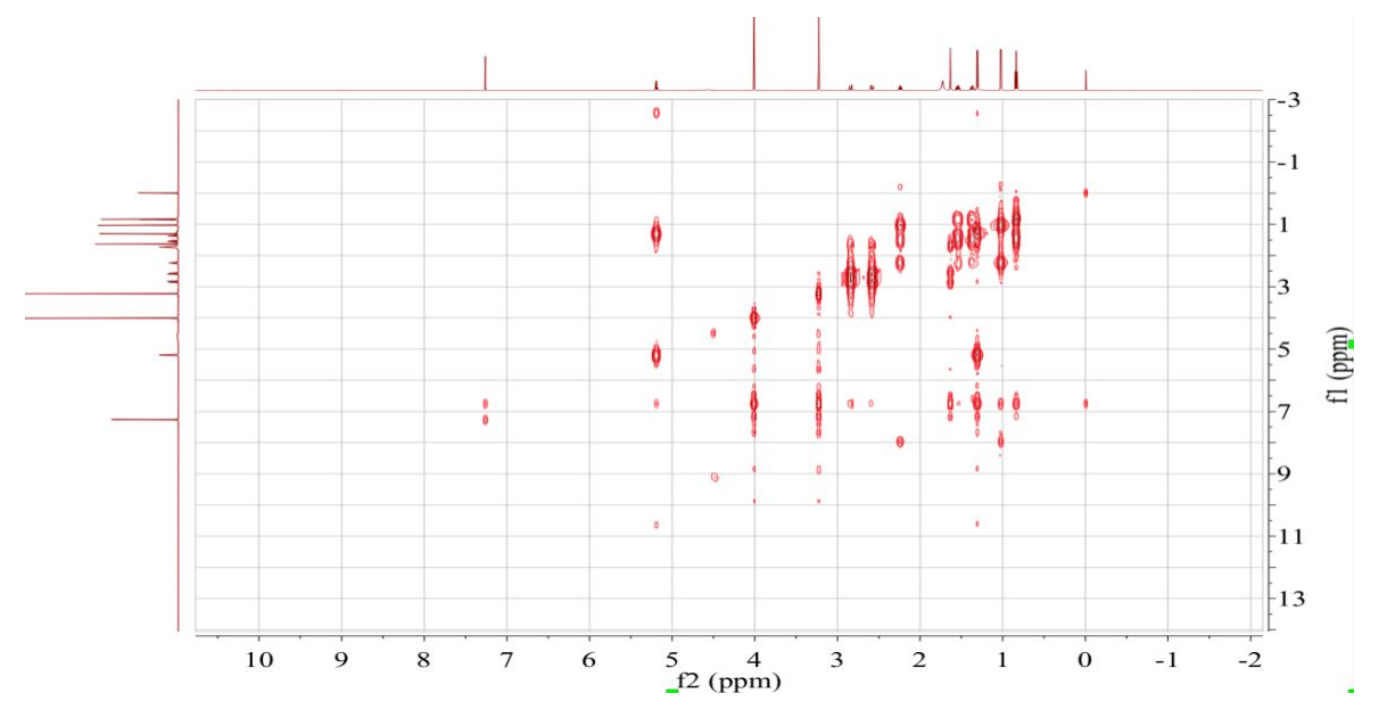

Figure S23. The ${ }^{1} \mathrm{H}_{-}{ }^{1} \mathrm{H}$ COSY spectrum of aspernone B (3) in $\mathrm{CDCl}_{3}$

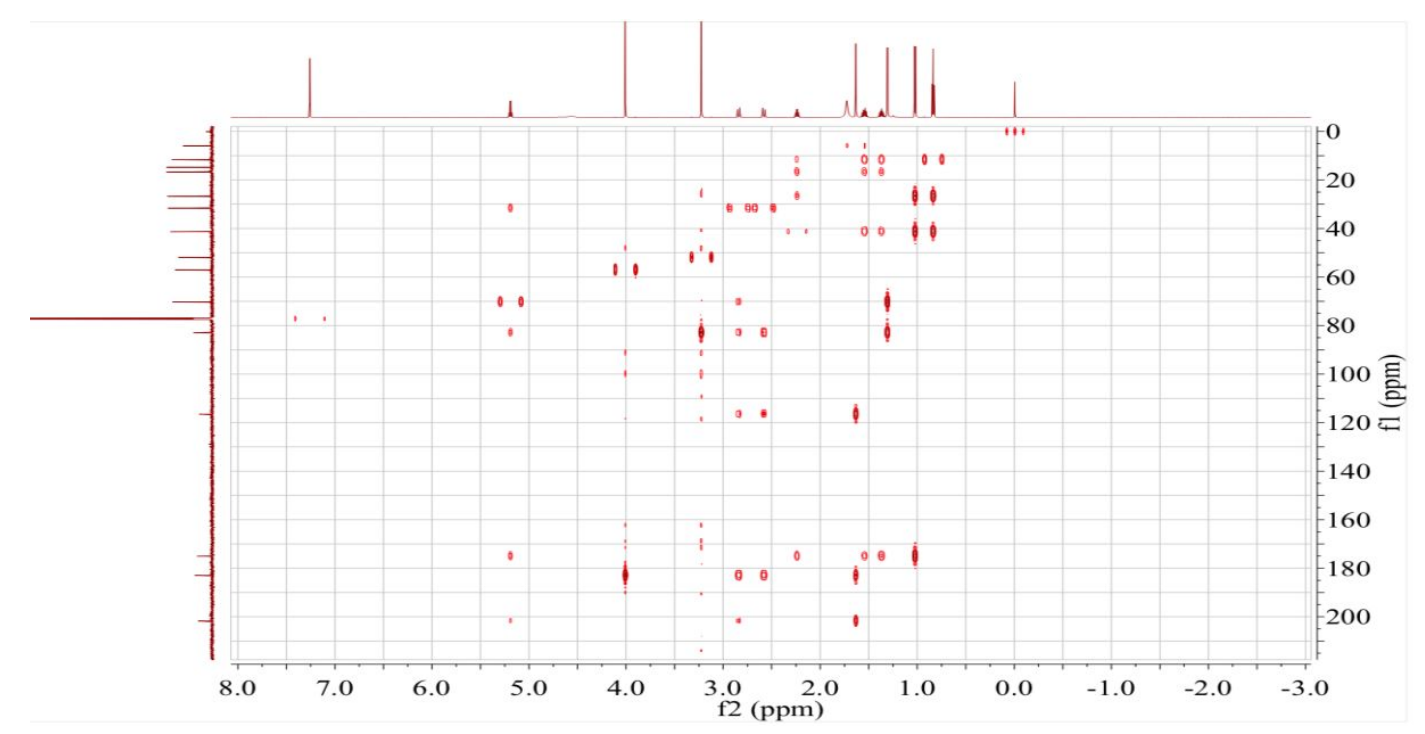

Figure S24. The $\mathrm{HMBC}$ spectrum of aspernone $\mathrm{B}(\mathbf{3})$ in $\mathrm{CDCl}_{3}$ 


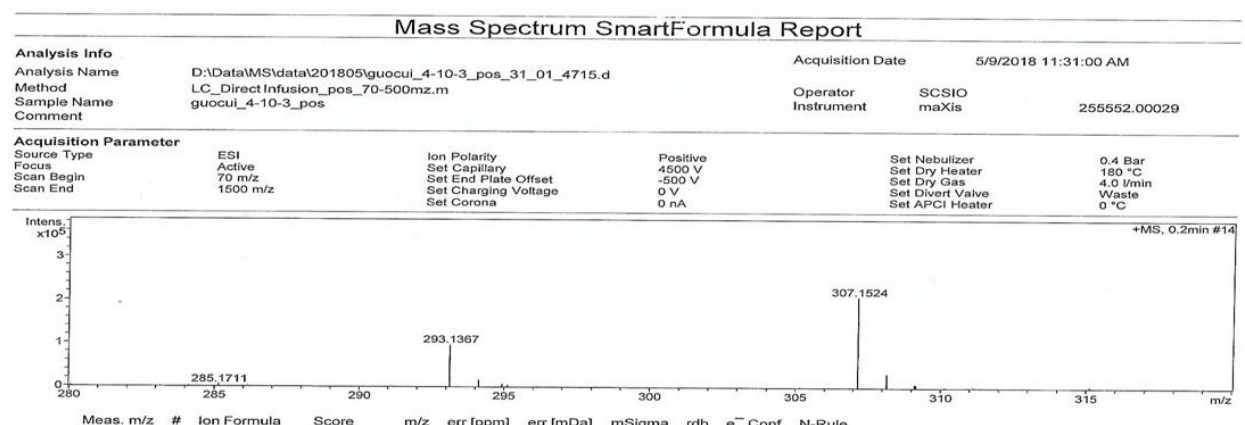

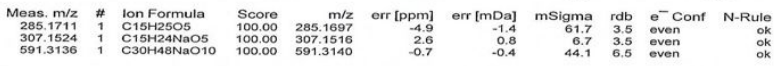

Figure S25. The HRESIMS spectrum of aspernone B (3)

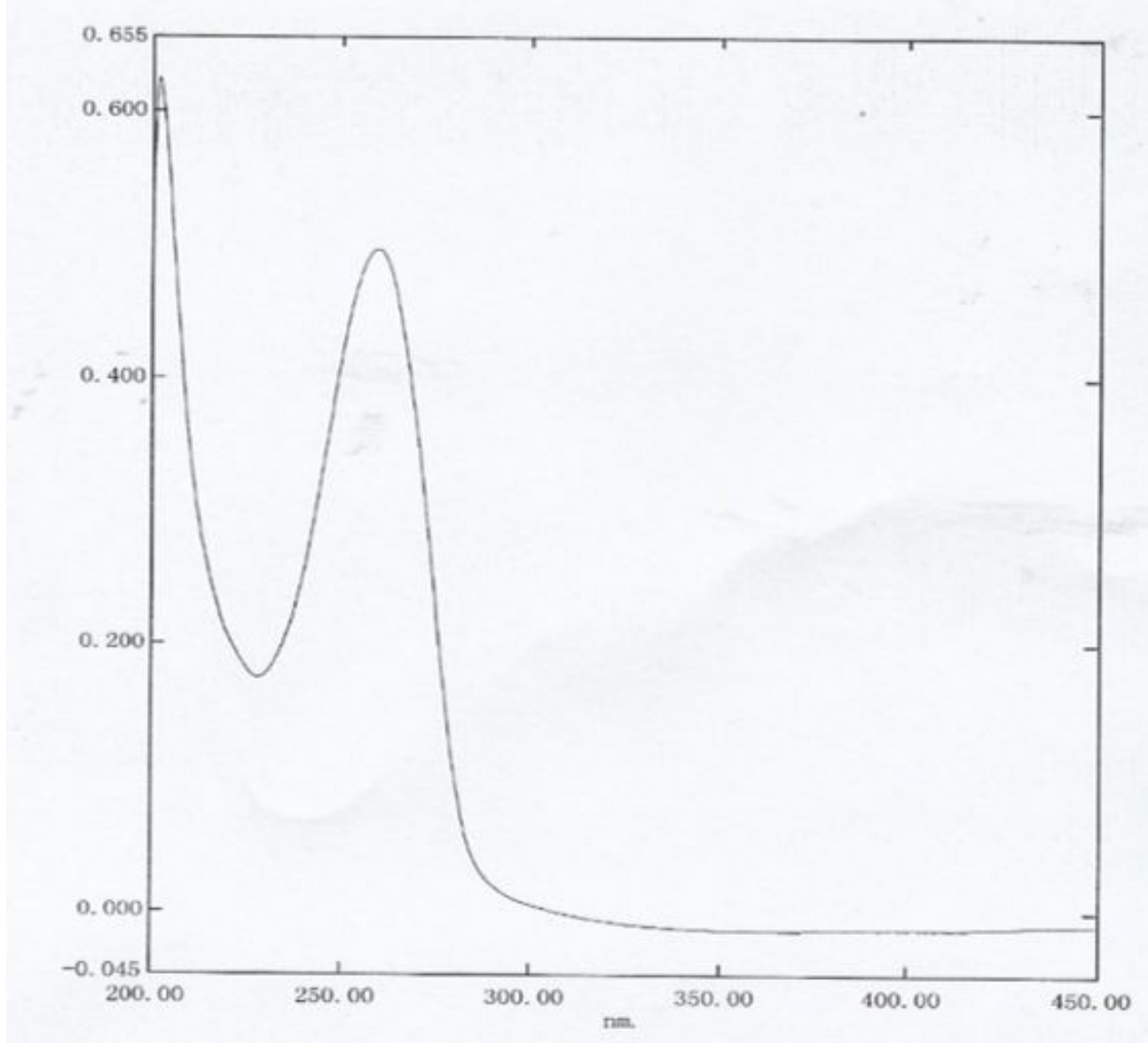

\begin{tabular}{|r|r|r|r|r|}
\hline No. & P/V & 波长 $(\mathrm{nm})$ & 吸收值 & 措还 \\
\hline 1 & $(\boldsymbol{T})$ & 259.80 & 0.496 & \\
\hline 2 & $\boldsymbol{T}$ & 201.80 & 0.623 & \\
\hline 3 & $\mathbf{3}$ & 228.00 & 0.175 & \\
\hline
\end{tabular}

Figure S26. The UV spectrum of aspernone B (3) 


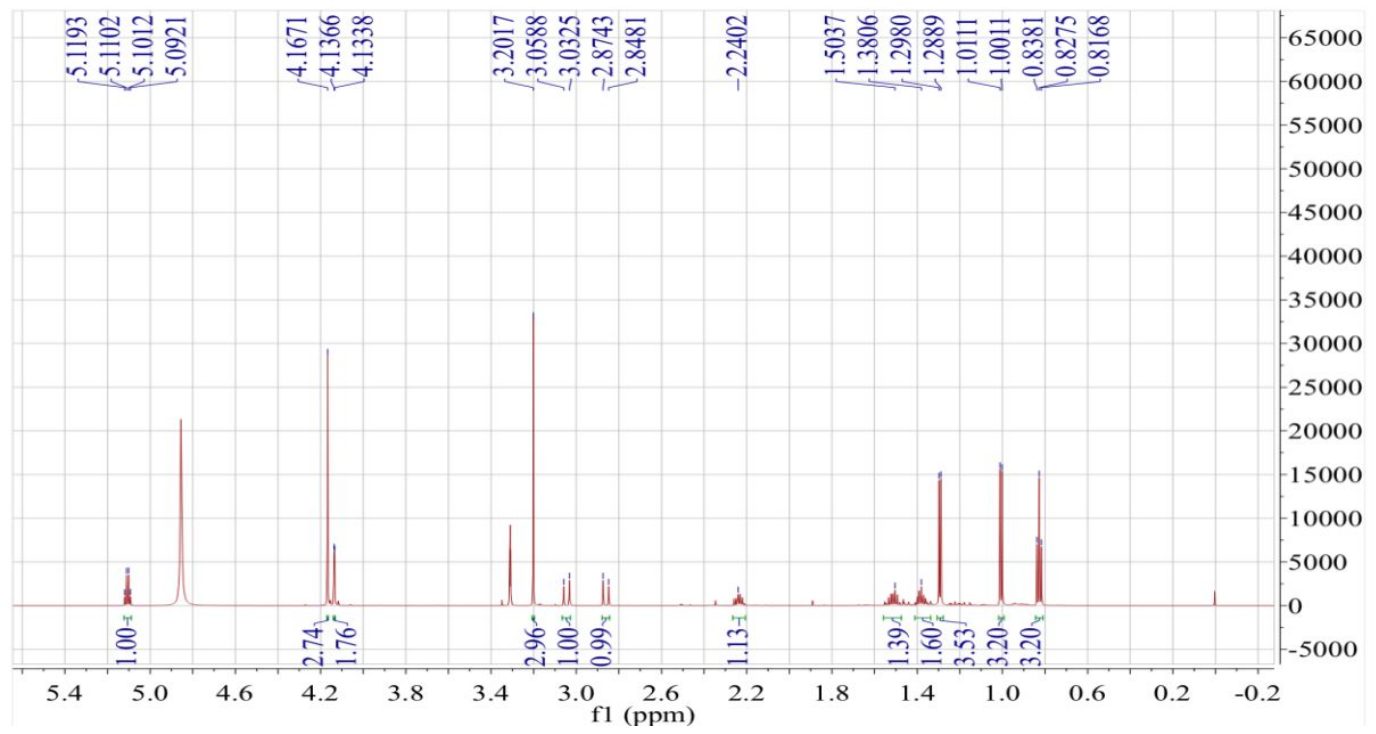

Figure S27. The ${ }^{1} \mathrm{H}$ NMR spectrum of aspernone $\mathrm{C}(4) \mathrm{inCD}_{3} \mathrm{OD}$

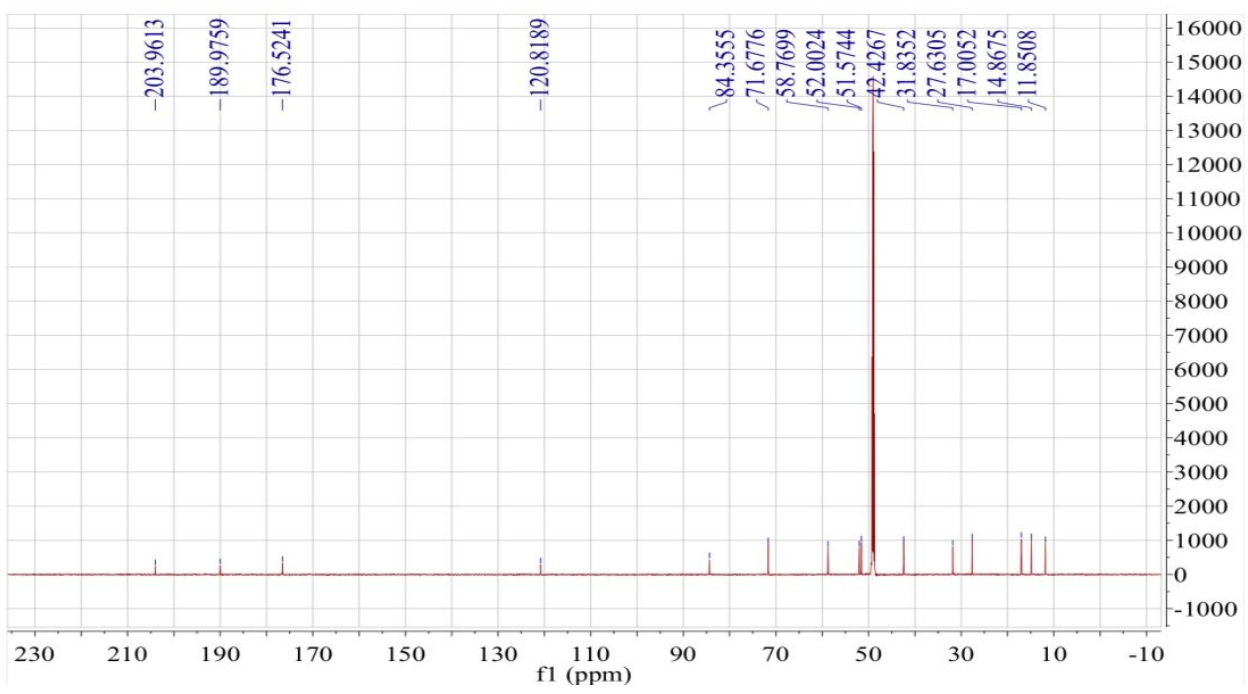

Figure S28. The ${ }^{13} \mathrm{C}$ NMR spectrum of aspernone $\mathrm{C}(4)$ in $\mathrm{CD}_{3} \mathrm{OD}$

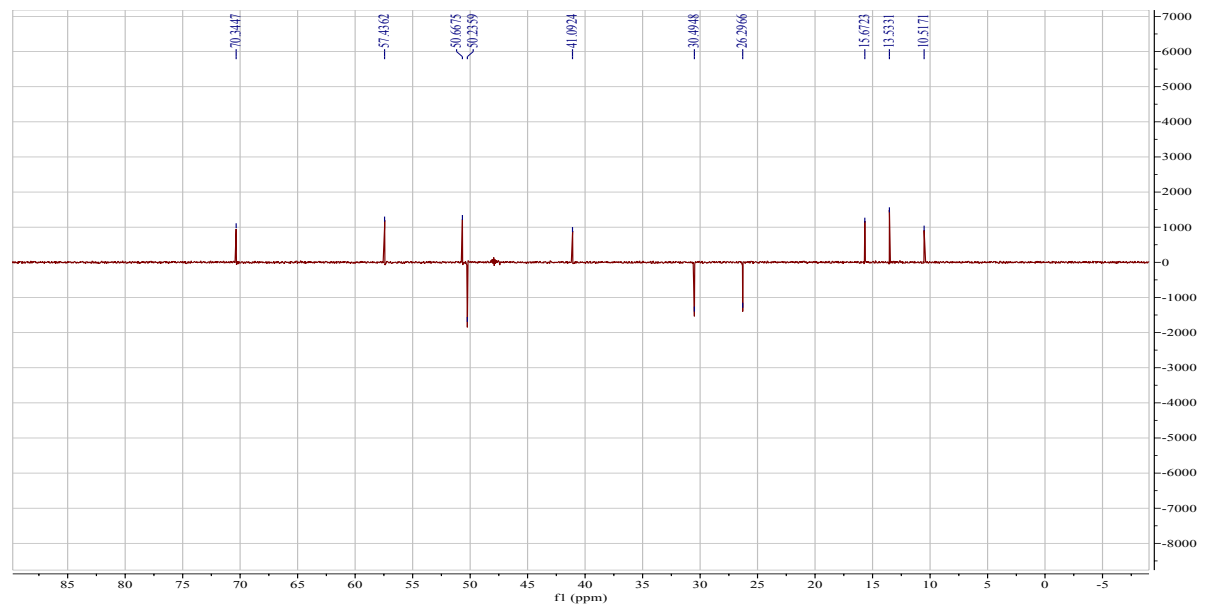

Figure S29. The DEPT spectrum of aspernone $\mathrm{C}(4)$ in $\mathrm{CD}_{3} \mathrm{OD}$ 


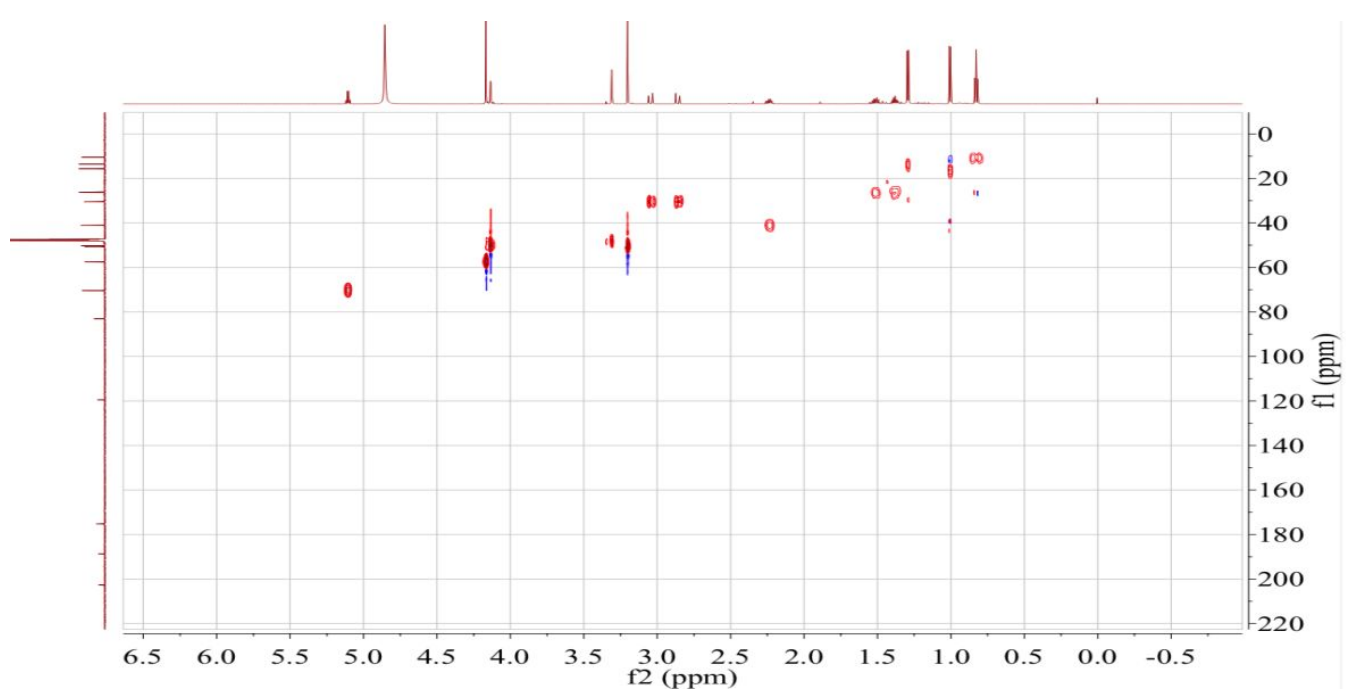

Figure S30. The HSQC spectrum of aspernone $\mathrm{C}(4)$ in $\mathrm{CD}_{3} \mathrm{OD}$

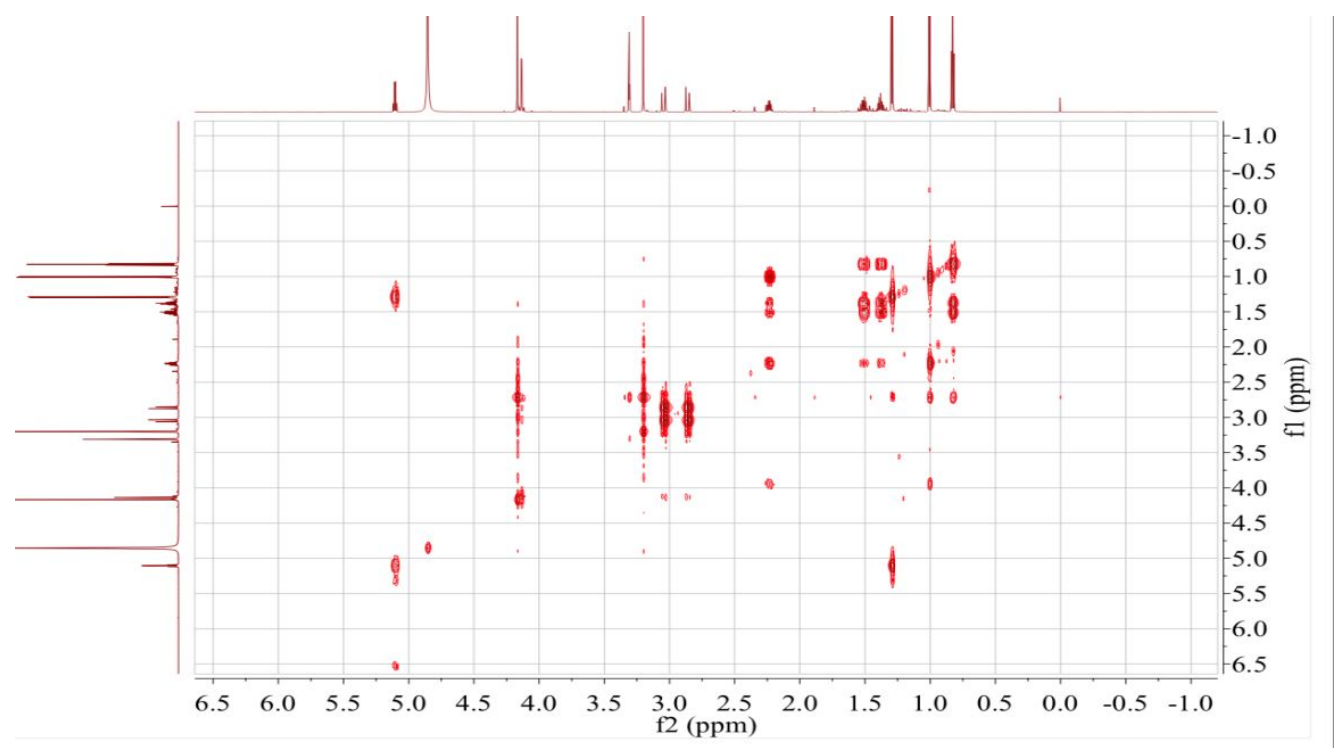

Figure S31. The ${ }^{1} \mathrm{H}-{ }^{-1} \mathrm{H}$ COSY spectrum of aspernone $\mathrm{C}(4)$ in $\mathrm{CD}_{3} \mathrm{OD}$

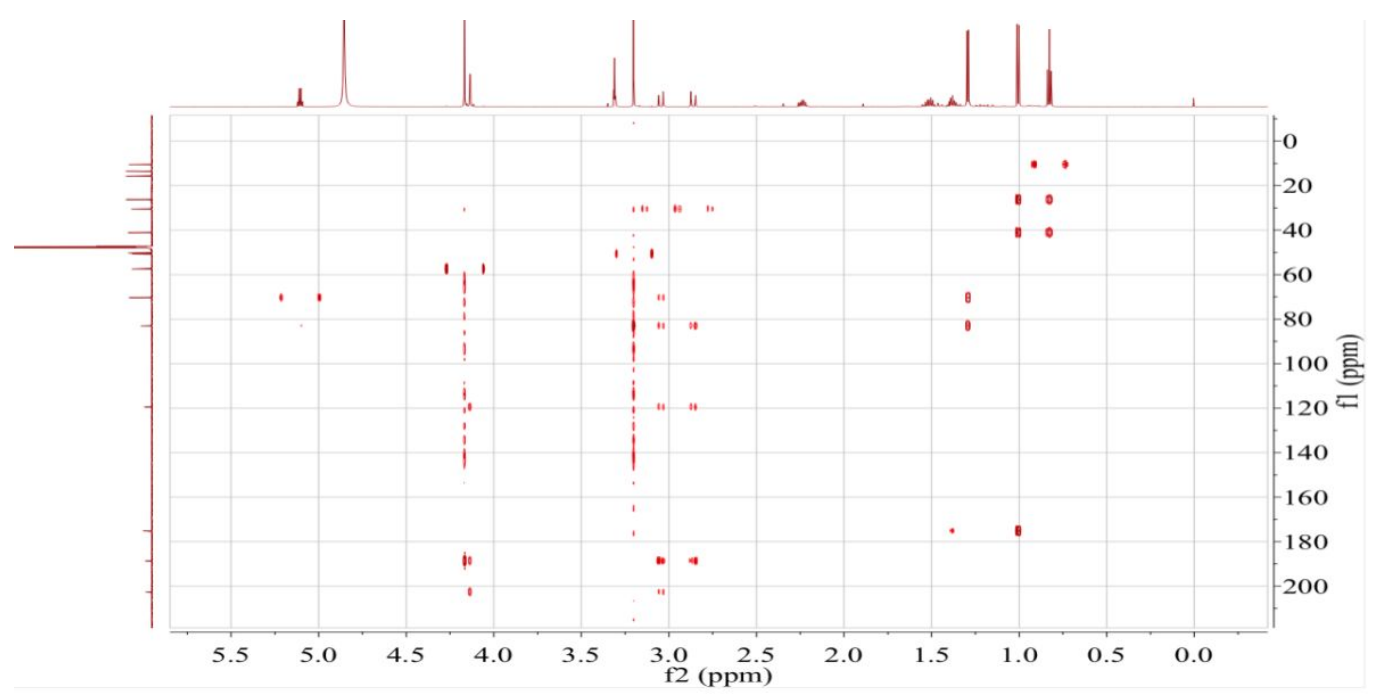

Figure S32. The $\mathrm{HMBC}$ spectrum of aspernone $\mathrm{C}(4)$ in $\mathrm{CD}_{3} \mathrm{OD}$ 


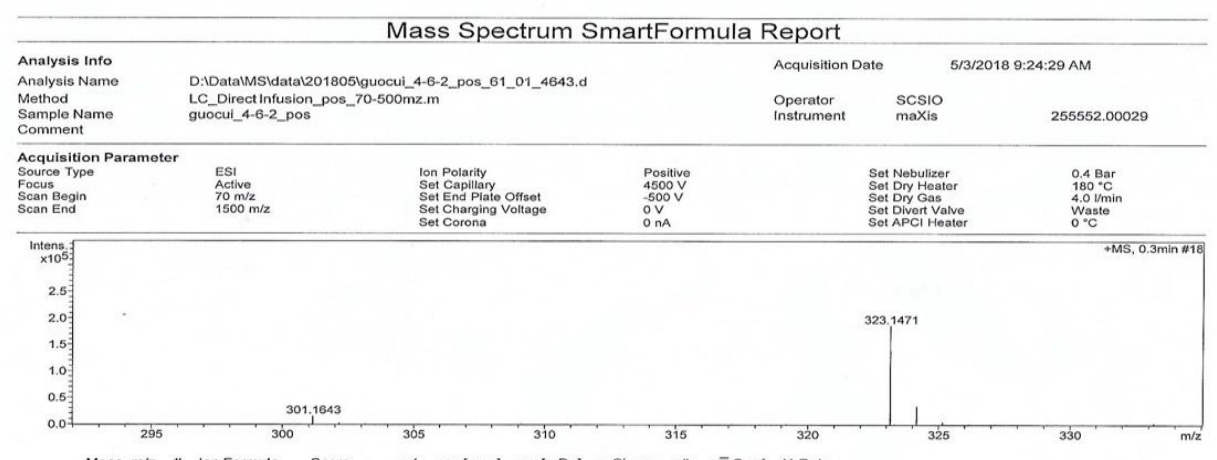

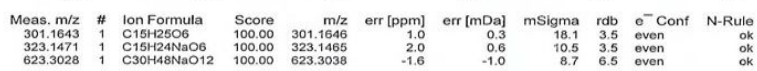

guocul_4-6.2-2005_61_01_4643.d.
Bruker Compass DataAnalysis 4.1

printed: $\quad$ 5/3/2018 9:29:13 AM

Figure S33. The HRESIMS spectrum of aspernone C (4)

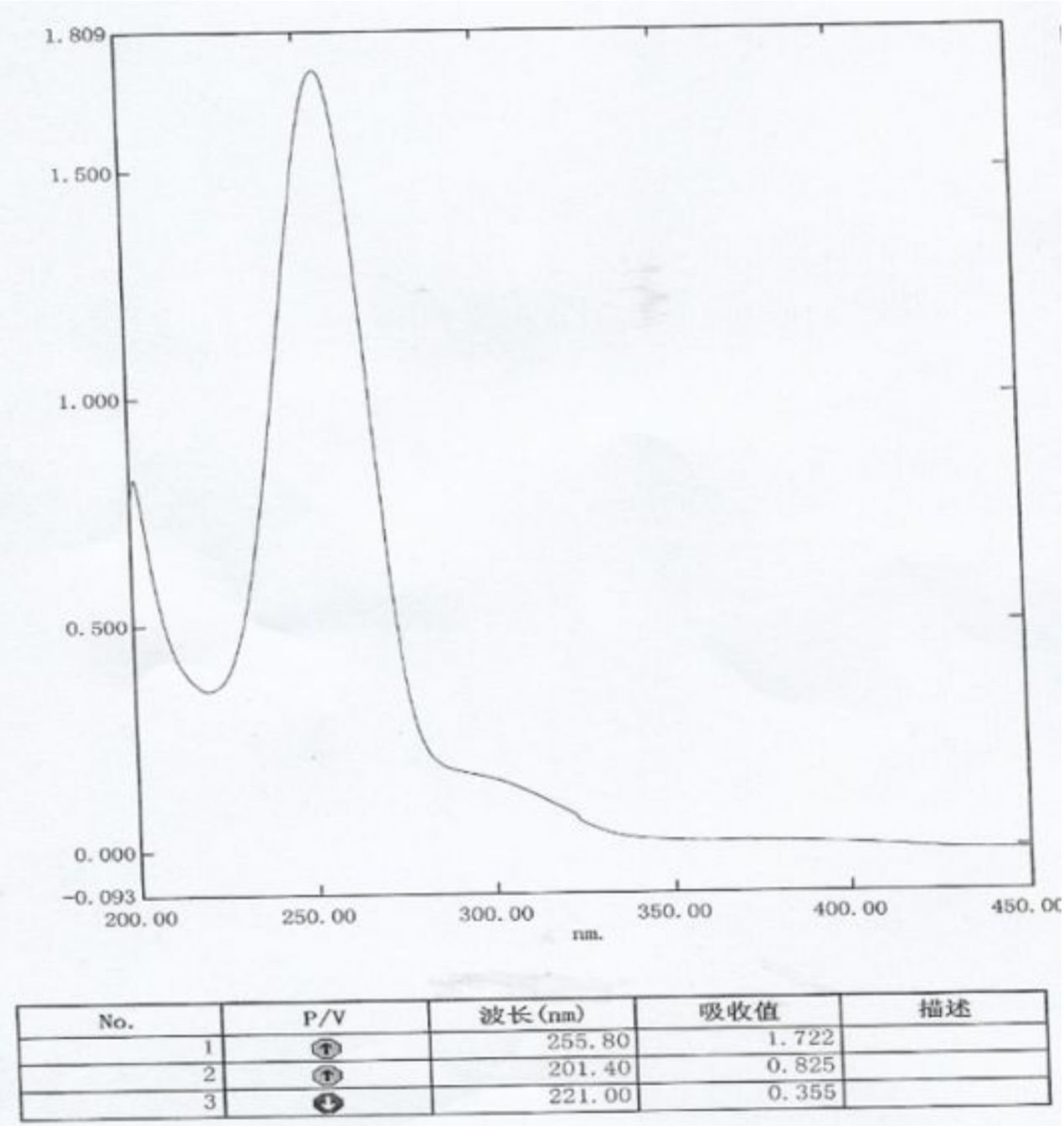

Figure S34. The UV spectrum of aspernone C (4) 


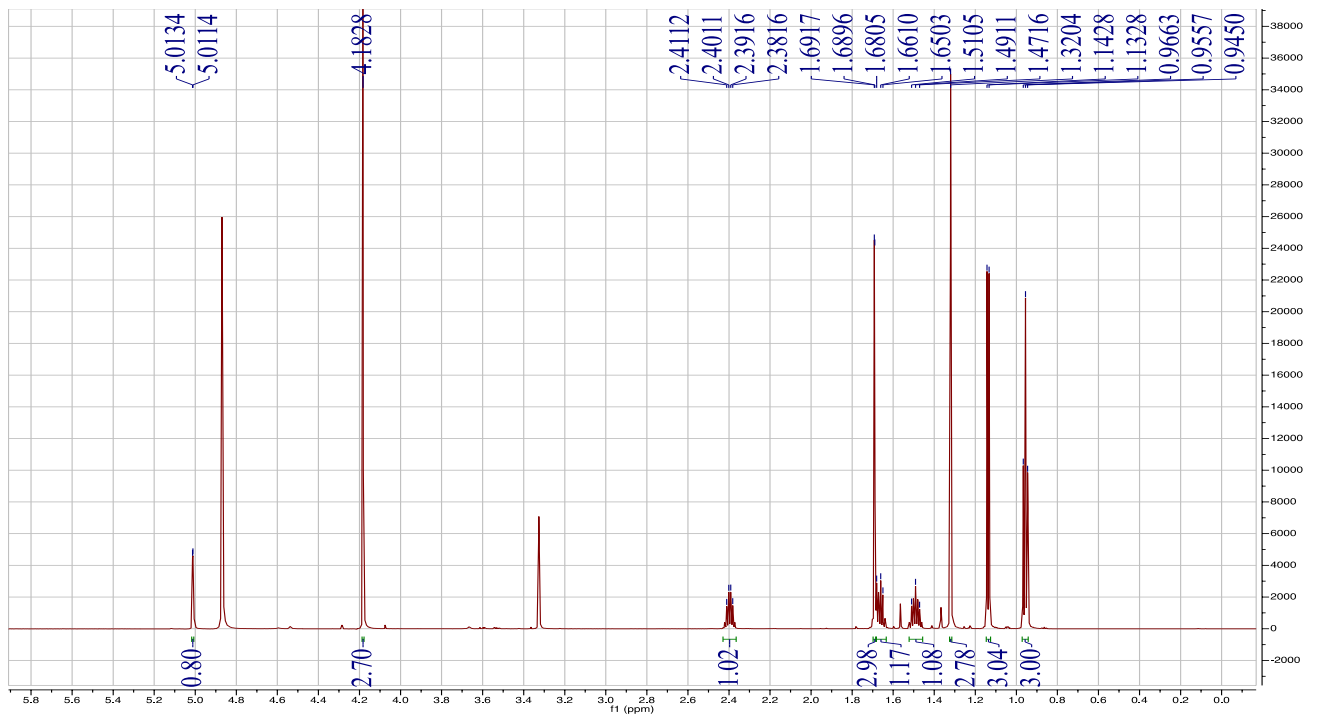

Figure S35. The ${ }^{1} \mathrm{H}$ NMR spectrum of aspernone $\mathrm{D}(\mathbf{5})$ in $\mathrm{CD}_{3} \mathrm{OD}$

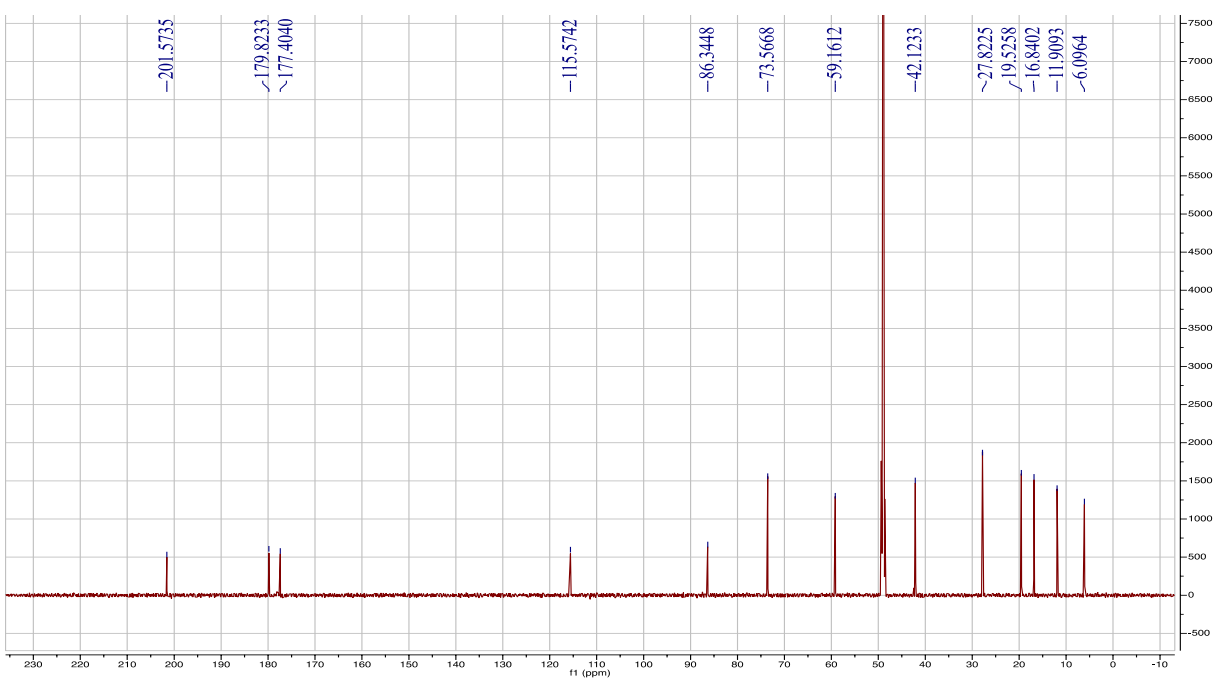

Figure S36. The ${ }^{13} \mathrm{C}$ NMR spectrum of aspernone $\mathrm{D}(\mathbf{5})$ in $\mathrm{CD}_{3} \mathrm{OD}$

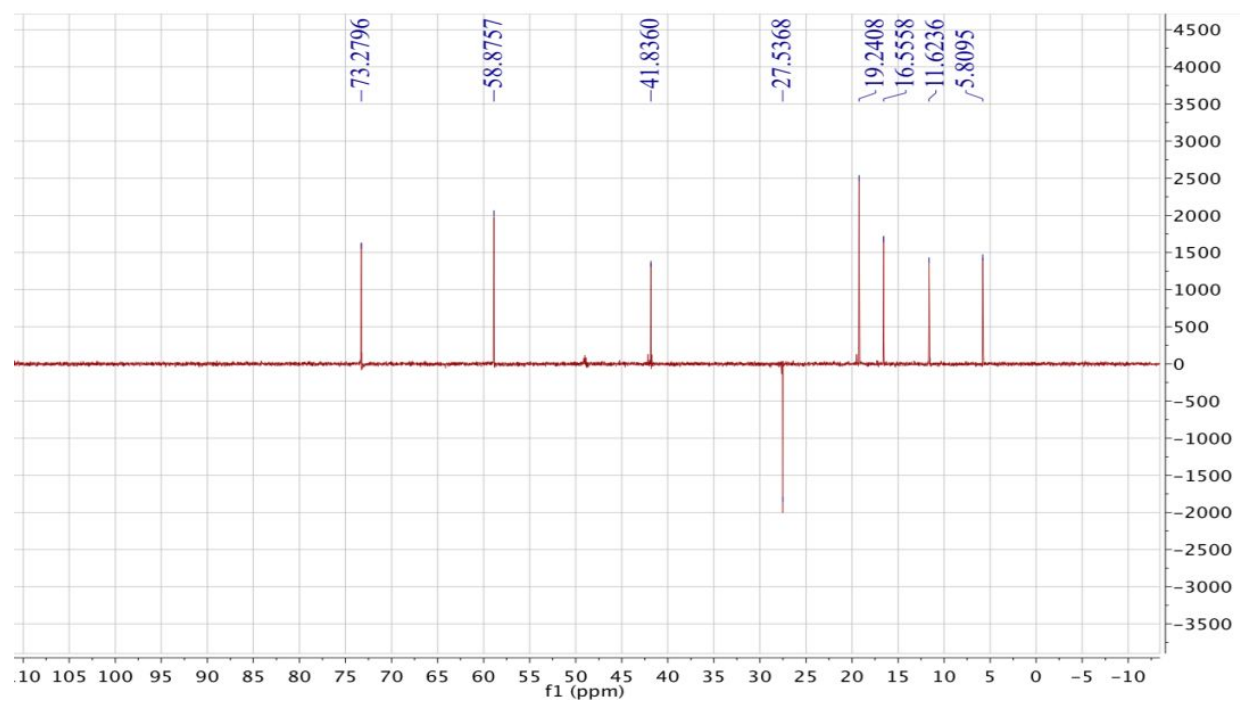

Figure S37. The DEPT spectrum of aspernone D (5) in $\mathrm{CD}_{3} \mathrm{OD}$ 


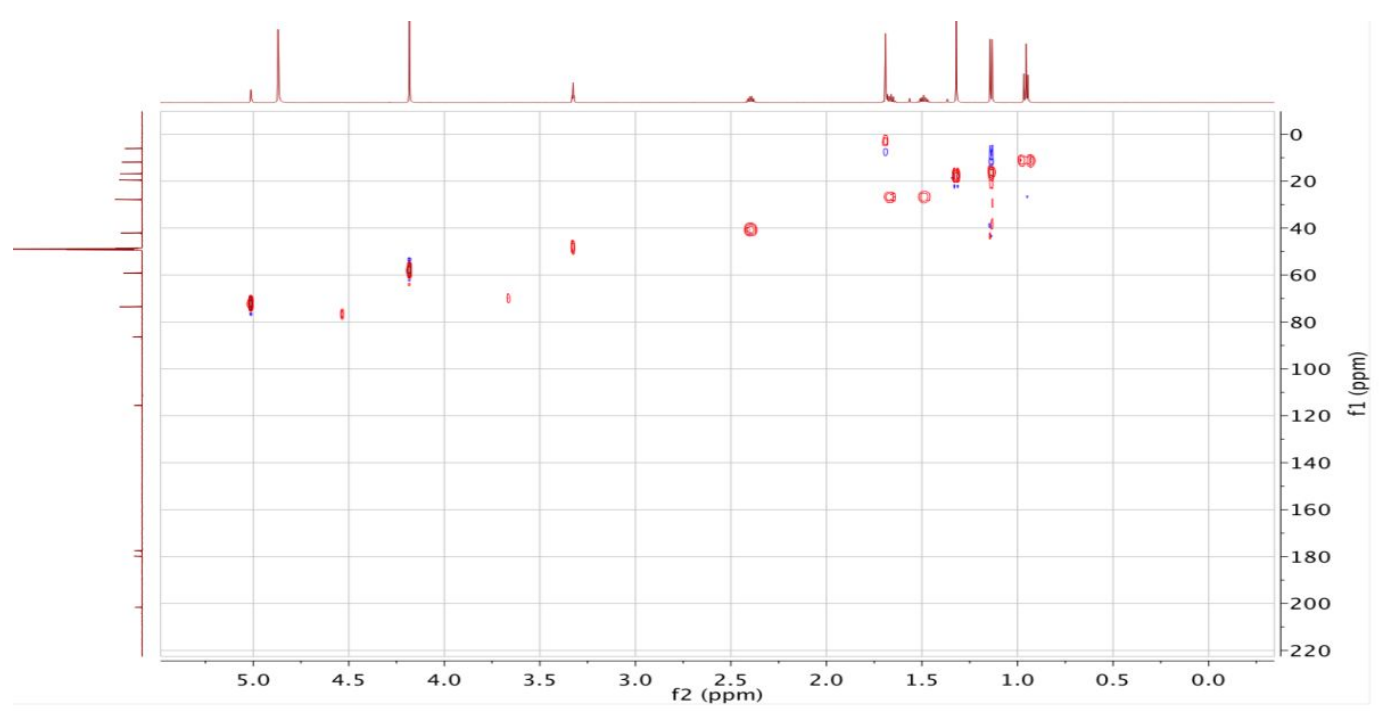

Figure S38. The HSQC spectrum of aspernone D (5) in $\mathrm{CD}_{3} \mathrm{OD}$

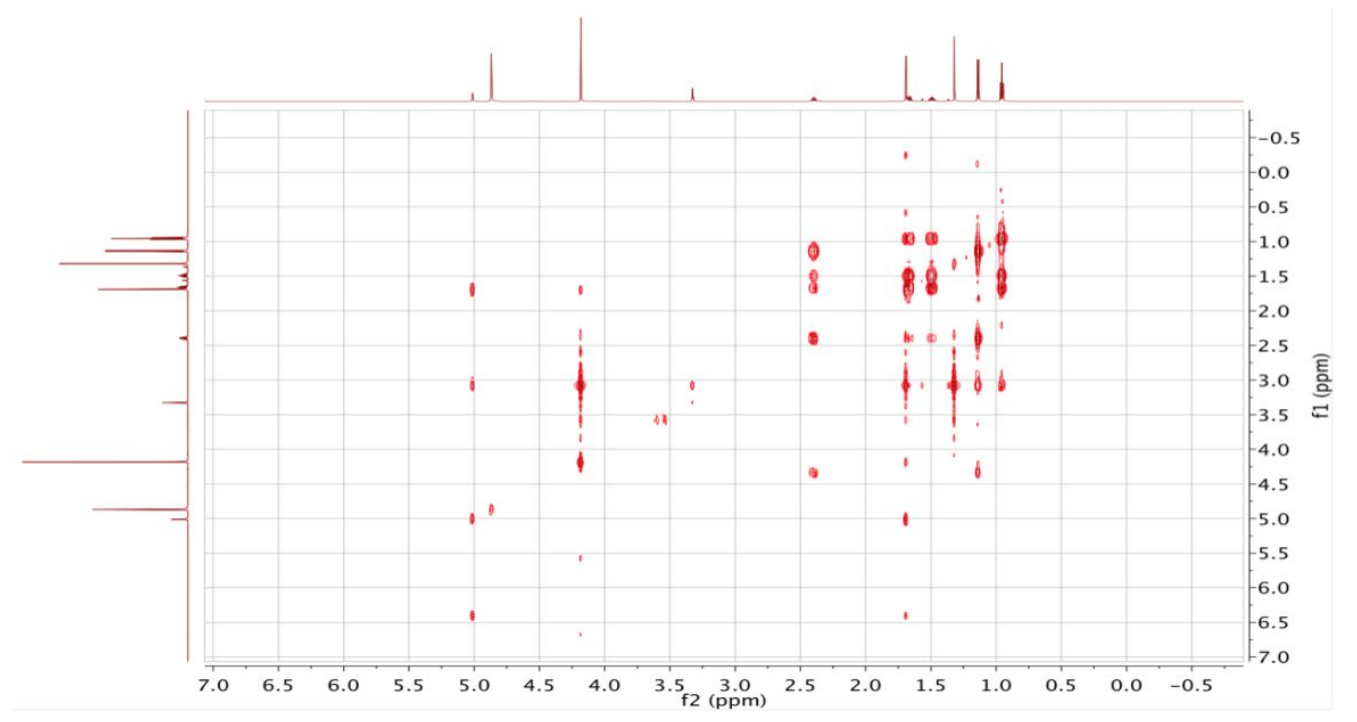

Figure S39. The ${ }^{1} \mathrm{H}-{ }^{1} \mathrm{H}$ COSY spectrum of aspernone $\mathrm{D}(\mathbf{5})$ in $\mathrm{CD}_{3} \mathrm{OD}$

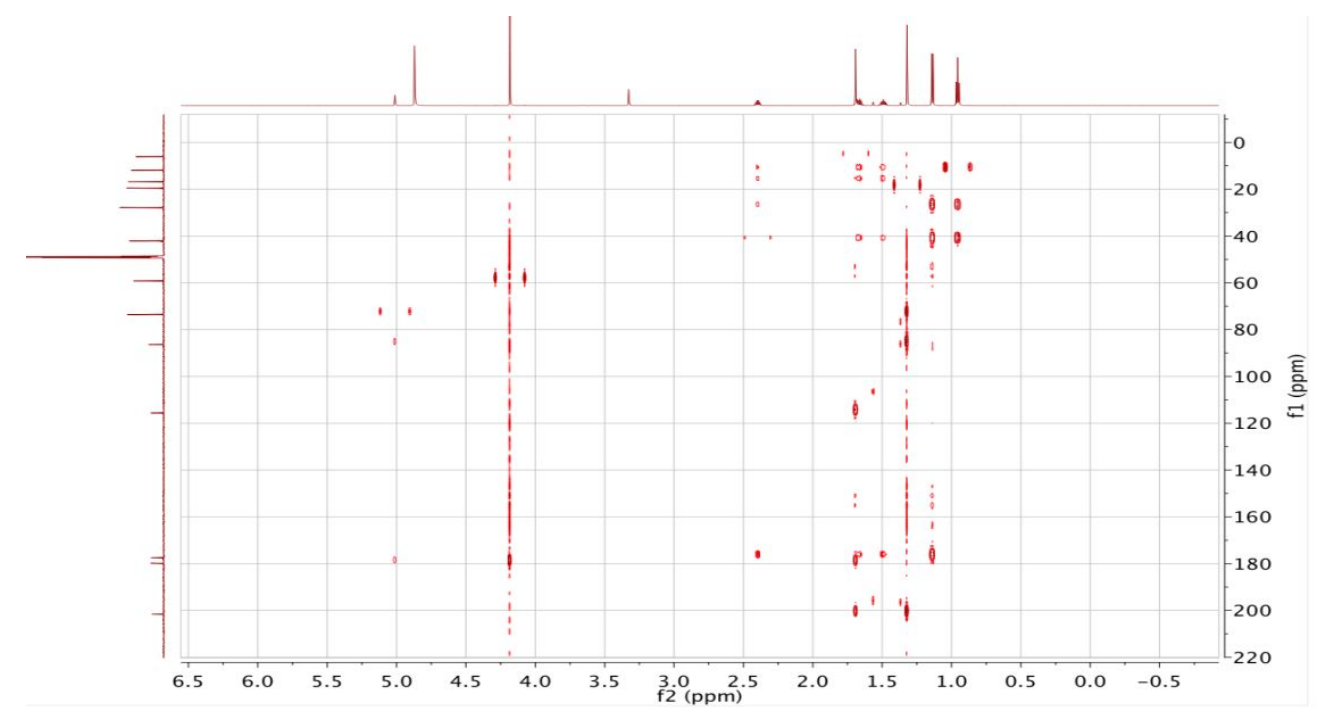

Figure S40. The HMBC spectrum of aspernone D (5) in $\mathrm{CD}_{3} \mathrm{OD}$ 


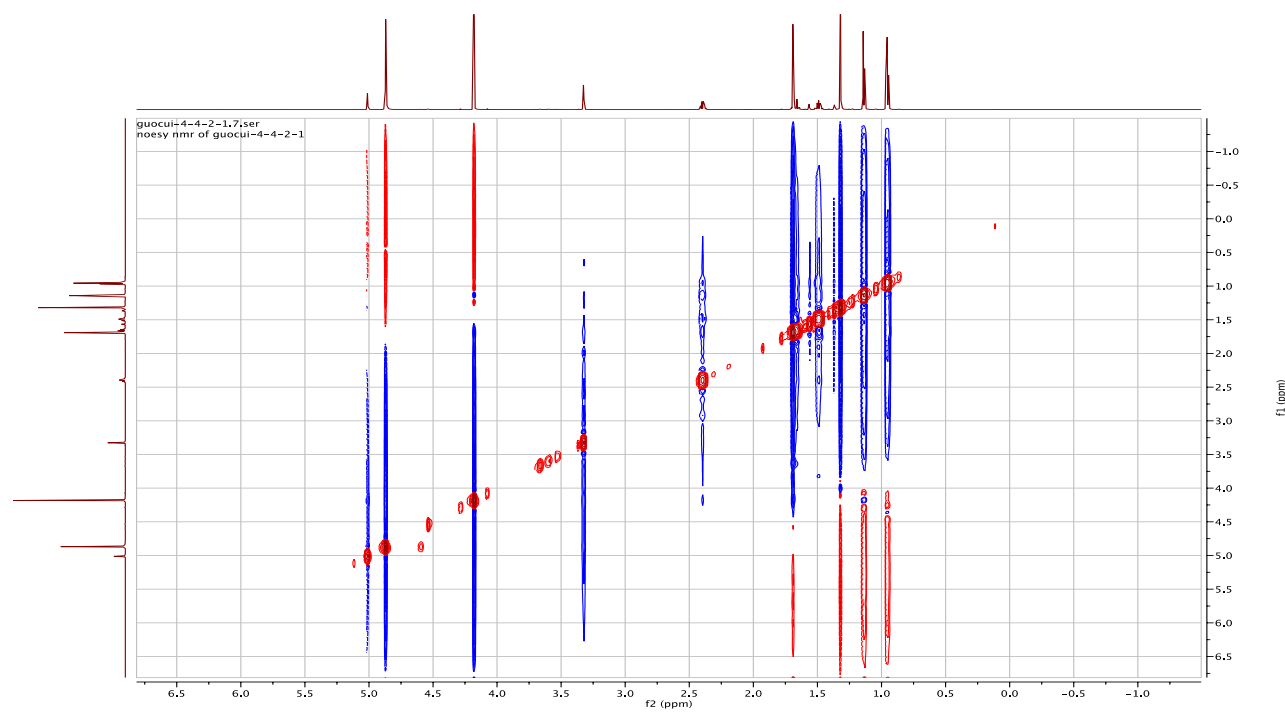

Figure S41. The NOESY spectrum of aspernone D (5) in $\mathrm{CD}_{3} \mathrm{OD}$

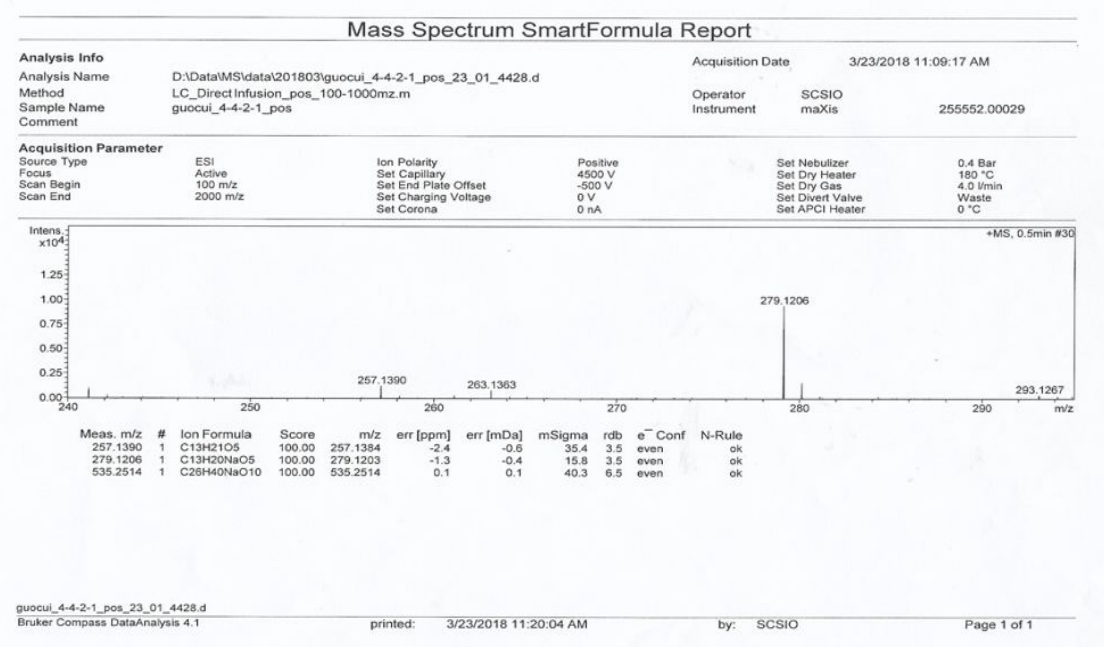

Figure S42. The HRESIMS spectrum of aspernone D (5) 


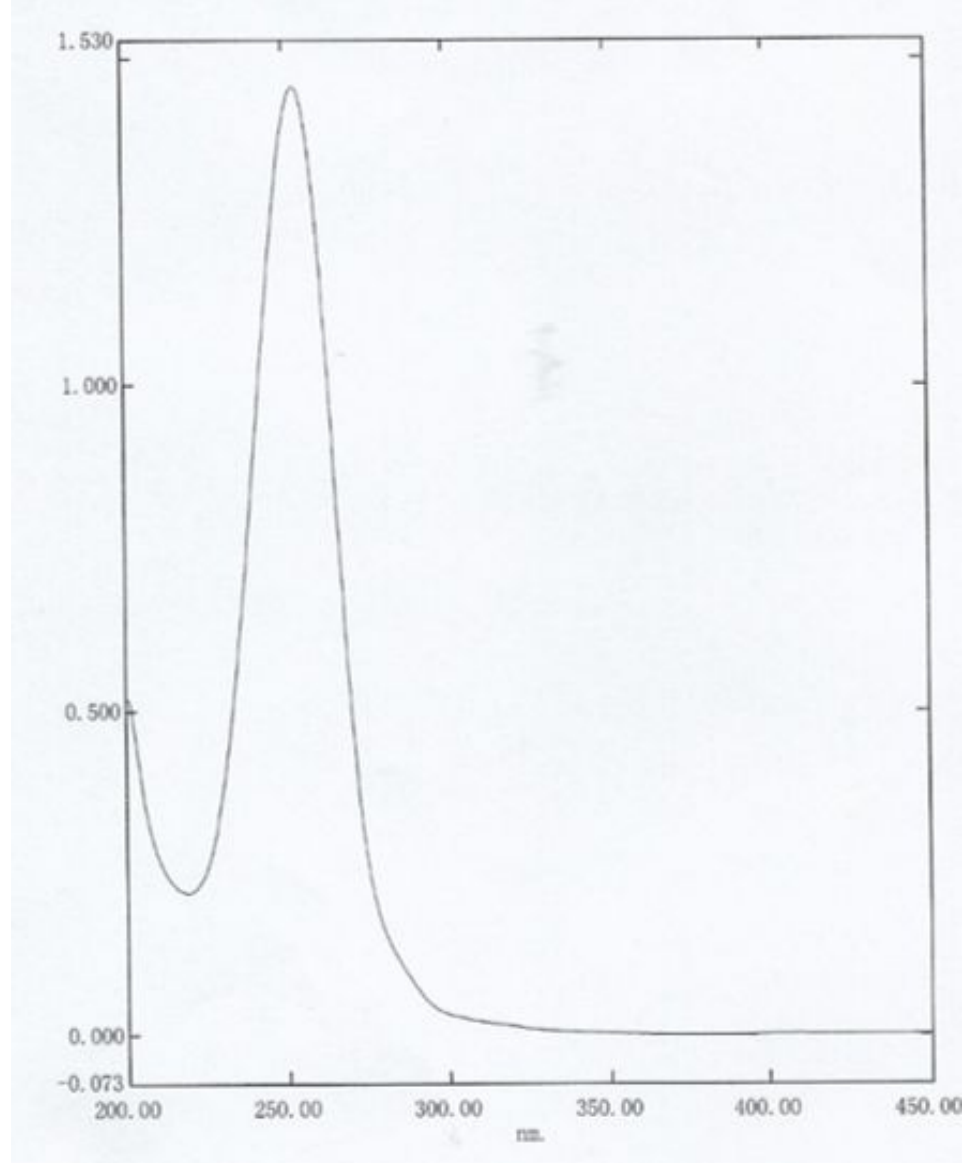

\begin{tabular}{|c|c|c|c|c|}
\hline No. & $\mathrm{P} / \mathrm{V}$ & 活长 (nn) & 吸收值 & 措达 \\
\hline 1 & (1) & 253.60 & 1.457 & \\
\hline 2 & 0 & 219.20 & 0.219 & \\
\hline
\end{tabular}

Figure S43. The UV spectrum of aspernone D (5)

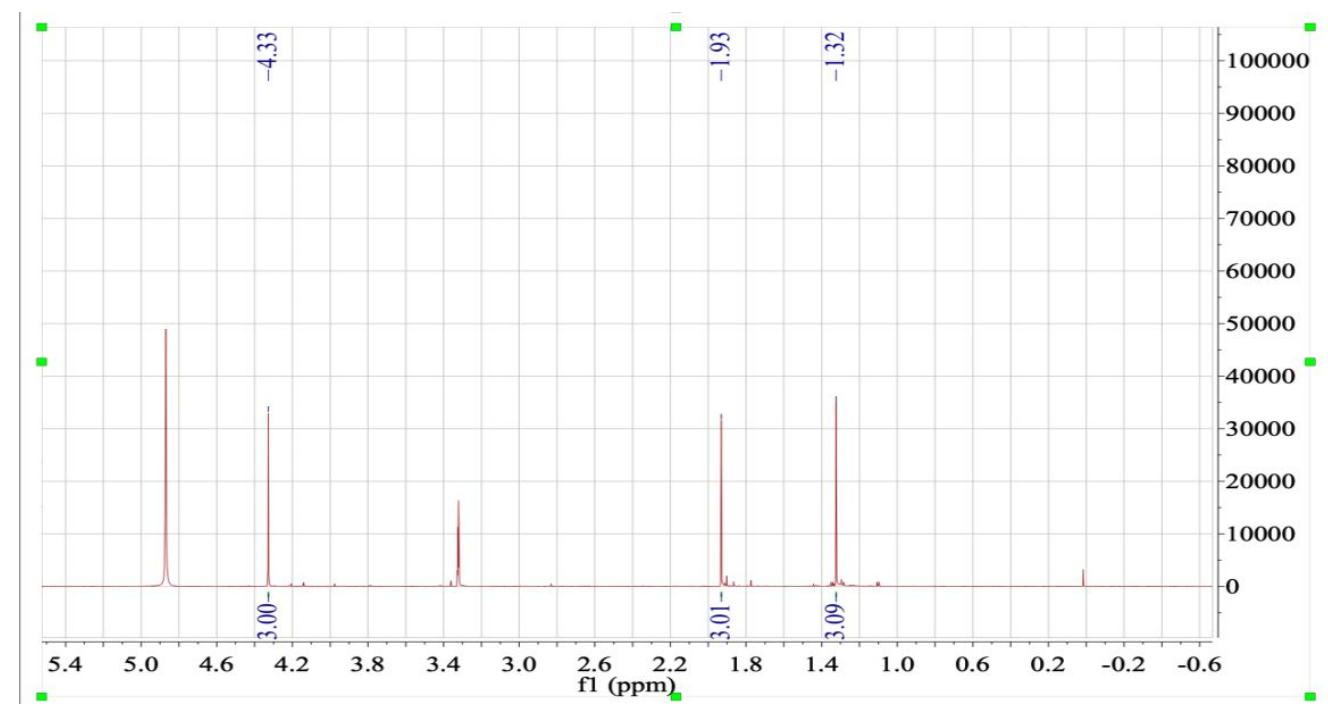

Figure S44. The ${ }^{1} \mathrm{H}$ NMR spectrum of aspernone $\mathrm{E}(6)$ in $\mathrm{CD}_{3} \mathrm{OD}$ 


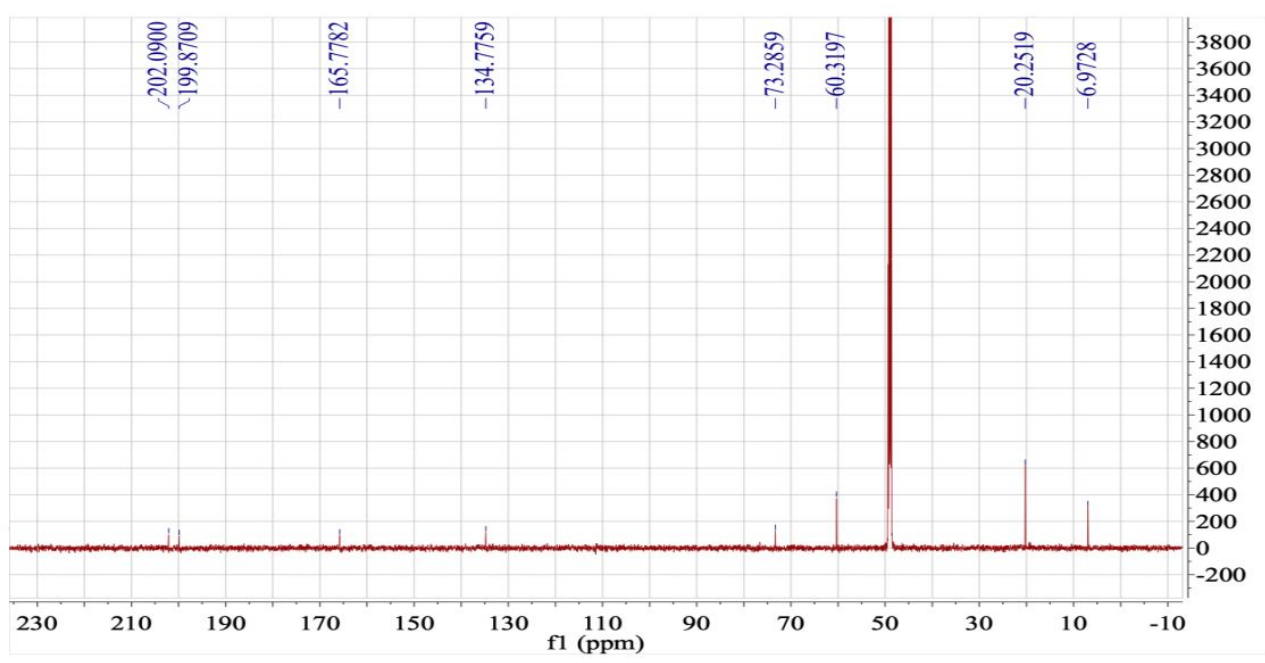

Figure S45. The ${ }^{13} \mathrm{C}$ NMR spectrum of aspernone $\mathrm{E}(6)$ in $\mathrm{CD}_{3} \mathrm{OD}$

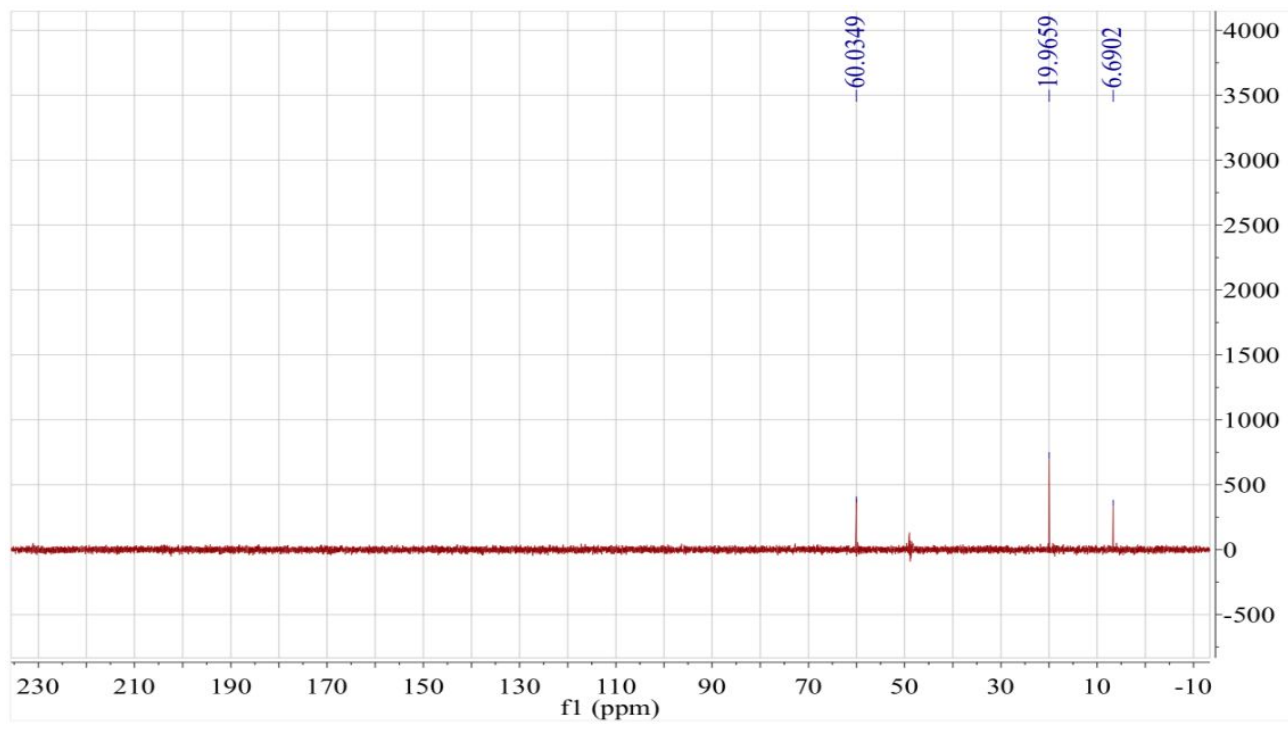

Figure S46. The DEPT spectrum of aspernone $\mathrm{E}(6)$ in $\mathrm{CD}_{3} \mathrm{OD}$

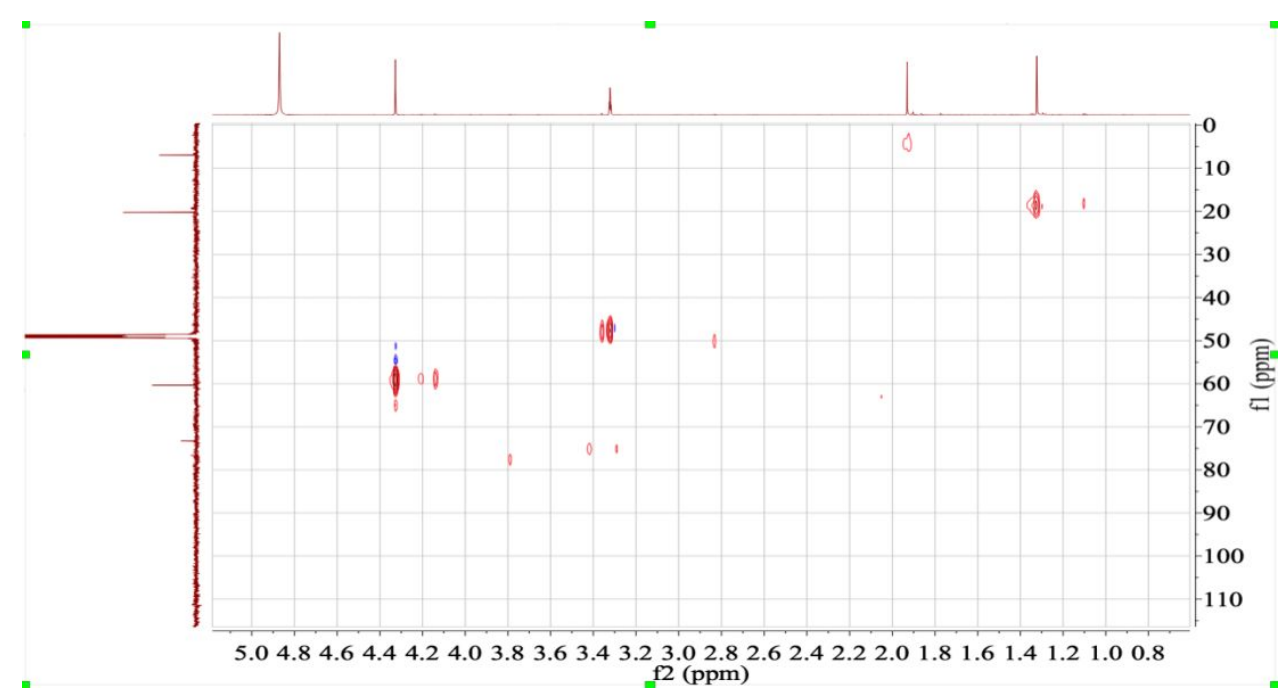

Figure S47. The HSQC spectrum of aspernone $\mathrm{E}(\mathbf{6})$ in $\mathrm{CD}_{3} \mathrm{OD}$ 


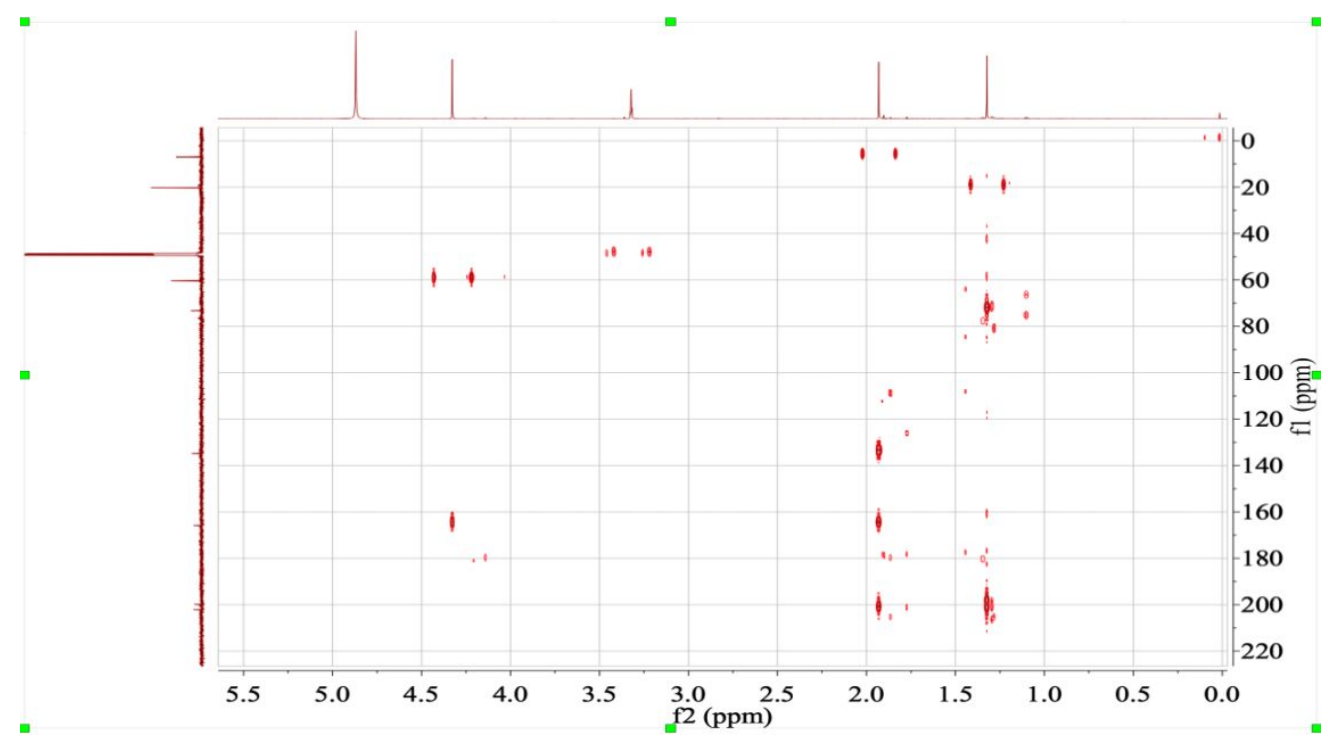

Figure S48. The HMBC spectrum of aspernone $\mathrm{E}(\mathbf{6})$ in $\mathrm{CD}_{3} \mathrm{OD}$

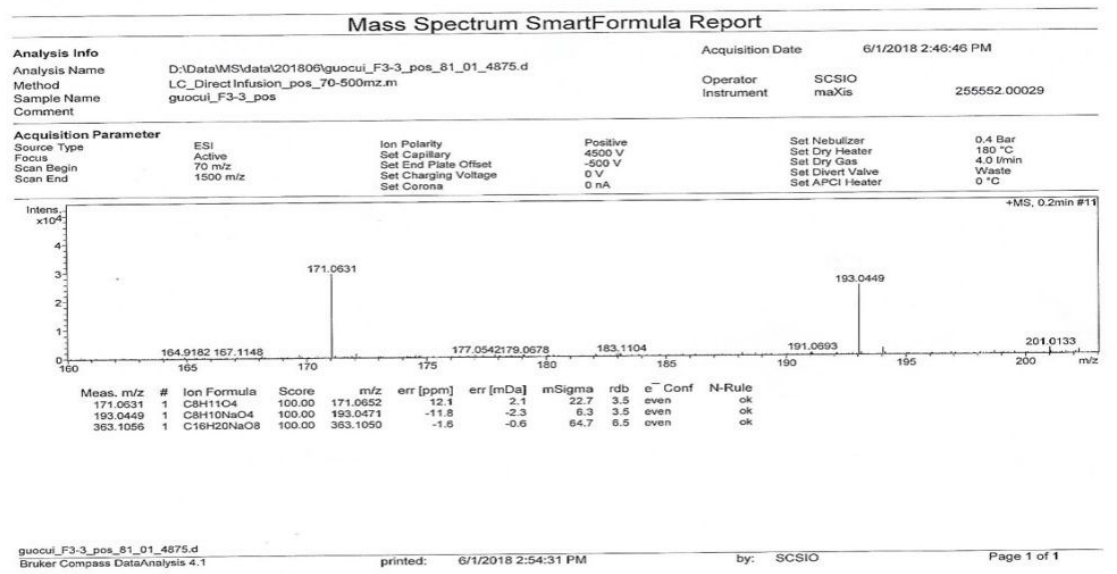

Figure S49. The HRESIMS spectrum of aspernone E (6) 


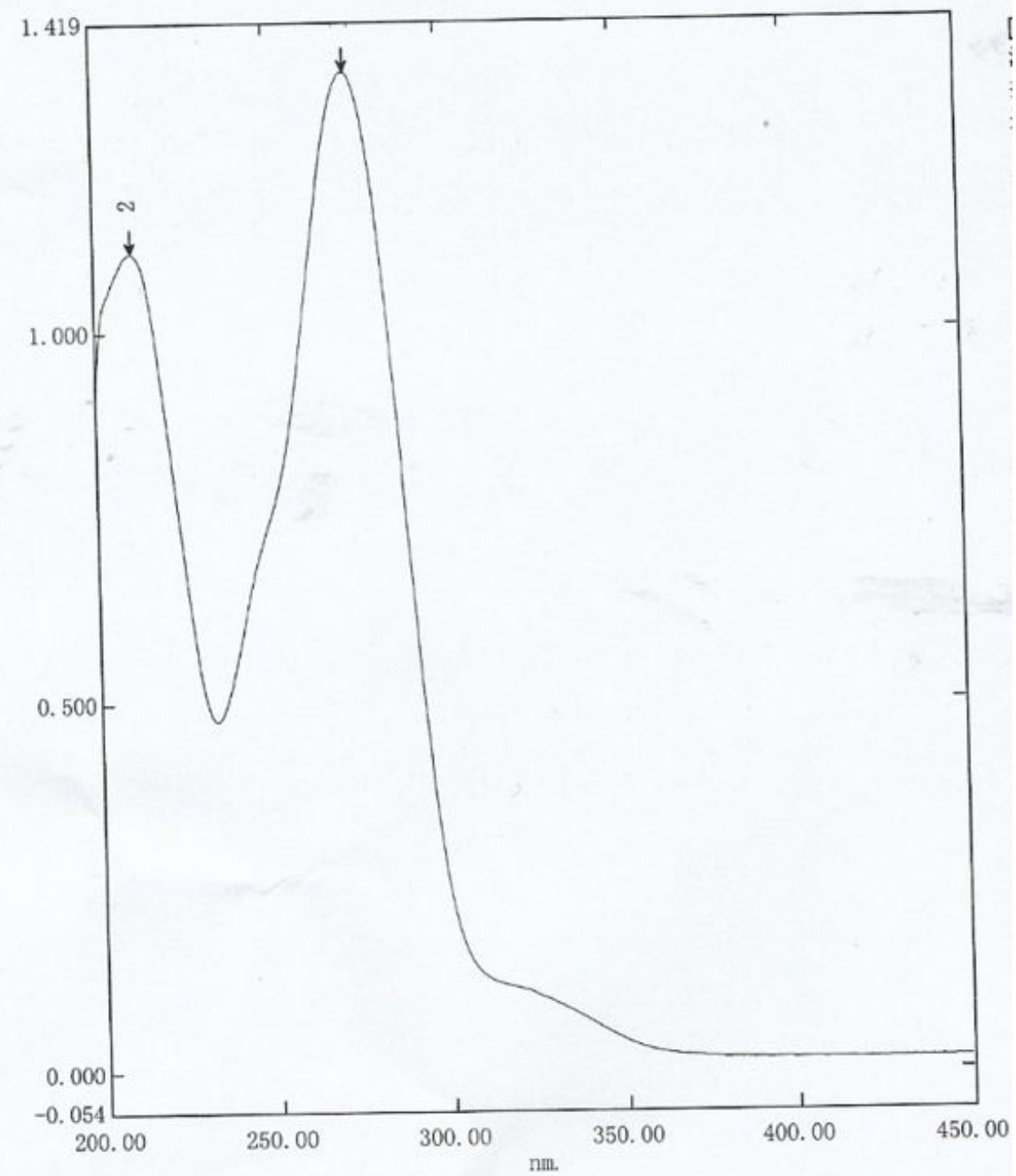

\begin{tabular}{|r|r|r|r|l|}
\hline No. & $\mathrm{P} / \mathrm{V}$ & 波长 $(\mathrm{nm})$ & 吸收值 & 描述 \\
\hline 1 & ( $)$ & 273.20 & 1.352 & \\
\hline 2 & ( & 211.20 & 1.109 & \\
\hline 3 & ( & 233.40 & 0.475 & \\
\hline
\end{tabular}

Figure S50. The UV spectrum of aspernone E(6) 